\title{
Distinguishing Aerosol Impacts on Climate Over the Past Century
}

\author{
Dorothy Koch \\ NASA Goddard Institute for Space Studies, Columbia University, New York, NY, USA \\ Surabi Menon \\ Lawrence Berkeley National Laboratory, Berkeley, CA, USA \\ Anthony Del Genio \\ NASA Goddard Institute for Space Studies, New York, NY, USA \\ Reto Ruedy \\ Sigma Space Partners LLC, New York, NY, USA \\ Igor Alienov \\ Columbia University, New York, NY, USA \\ Gavin A. Schmidt \\ NASA Goddard Institute for Space Studies, New York, NY, USA
}

August 2008

The work at Lawrence Berkeley National Laboratory was supported by the Office of Science at the U.S. Department of Energy under Contract No. DE-AC02-05CH11231 


\title{
Distinguishing Aerosol Impacts on Climate
}

\section{Over the Past Century}

\author{
Dorothy Koch *
}

NASA Goddard Institute for Space Studies, Columbia University, New

Surabi MEnon

Lawrence Berkeley National Laboratory, Berkeley, CA, USA

\section{Anthony Del Genio}

NASA Goddard Institute for Space Studies, New York, NY, USA

$$
\text { RETO RuEDY }
$$

Sigma Space Partners LLC, New York, NY, USA

IgOR ALIENOV

Columbia University, New York, NY, USA

$$
\text { Gavin A. SchmidT }
$$

NASA Goddard Institute for Space Studies, New York, NY, USA 


\begin{abstract}
Aerosol direct (DE), indirect (IE), and black carbon-snow albedo (BAE) effects on climate between 1890 and 1995 are compared using equilibrium aerosolclimate simulations in the Goddard Institute for Space Studies General Circulation Model coupled to a mixed layer ocean. Pairs of control(1890)-perturbation(1995) with successive aerosol effects allow isolation of each effect. The experiments are conducted both with and without concurrent changes in greenhouse gases (GHG's). A new scheme allowing dependence of snow albedo on black carbon snow concentration is introduced.
\end{abstract}

The fixed GHG experiments global surface air temperature (SAT) changed $-0.2,-1.0$ and $+0.2^{\circ} \mathrm{C}$ from the DE, IE, and BAE. Ice and snow cover increased $1.0 \%$ from the IE and decreased $0.3 \%$ from the BAE. These changes were a factor of 4 larger in the Arctic. Global cloud cover increased by $0.5 \%$ from the IE.

Net aerosol cooling effects are about half as large as the GHG warming, and their combined climate effects are smaller than the sum of their individual effects. Increasing GHG's did not affect the IE impact on cloud cover, however they decreased aerosol effects on SAT by $20 \%$ and on snow/ice cover by $50 \%$; they also obscure the BAE on snow/ice cover.

Arctic snow, ice, cloud, and shortwave forcing changes occur mostly during summer-fall, but SAT, sea level pressure, and long-wave forcing changes occur

* Corresponding author address: Dorothy Koch, NASA Goddard Institute for Space Studies, Columbia University, 2880 Broadway, New York, NY 10025.

E-mail: dkoch@giss.nasa.gov 
during winter. An explanation is that aerosols impact the cryosphere during the warm-season but the associated SAT effect is delayed until winter. 


\section{Introduction}

Atmospheric aerosols have multiple and complex impacts on climate. Distinguishing and quantifying these effects remains a major challenge of climate studies. The net effect of aerosol changes in the 20th century on climate is thought to be cooling of surface air temperatures (SAT's), partially offsetting warming from increasing greenhouse gas (GHG) concentrations. However some aerosol effects can contribute to warming. Furthermore, aerosols and GHG's affect not only SAT's, but also clouds and hydrology, the cryosphere and atmospheric circulation. While the GHG changes affect these primarily via changes to the radiation/temperature, aerosols are thought to have additional "indirect" physical effects on clouds and cryosphere.

The best understood aerosol effect is the "direct" effect (DE), the scattering and absorption of radiation by aerosols suspended in the atmosphere. This effect cools the underlying surface, but if absorbing components are present, it can warm the local air-mass. Although the DE is best understood, uncertainties remain in emissions, model transport and removal, aerosol microphysics such as chemical mixing and size distribution, and aerosol optical properties. Thus, the range in the DE change from pre-industrial among recent aerosol models is -0.41 to $+0.04 \mathrm{Wm}^{-2}$, with larger spread among individual aerosol species (Schulz et al., 2006). Black carbon (BC) absorption and warming within the air column can also cause shifts in cloud distribution. This has been called the semi-direct effect and is included in models that have aerosol-radiation interaction.

Aerosols also increase cloud droplet number concentrations thereby increasing cloud albedo ("first indirect effect"); these are thought to reduce droplet size, suppress precipita- 
tion, increase cloud liquid water path and prolong cloud lifetime ("second indirect effect"). Since most clouds and pollution are low in the atmosphere, the overall effect is cooling. However, aerosol effects on ice clouds (e.g. Lohmann and Feichter, 2005) and on Arctic clouds (Garrett and Zhao, 2006; Lubin and Vogelmann, 2006) are of uncertain sign.

Dark absorbing aerosols, especially BC, deposited on snow or ice surfaces can reduce the surface albedo, promote melting and therefore warm the climate. A simple parameterization of albedo reduction by BC deposition was developed by Hansen and Nazarenko (2004), and used in climate model studies (Hansen et al. 2005, 2007). Jacobson (2004) also included dependence of snow albedo and model radiation on BC snow concentrations. A sophisticated BC-snow model was developed by Flanner et al. (2007), who estimated a larger BC impact on albedo and greater efficacy (temperature change per forcing). The larger efficacy was attributed to the positive snow structure feedbacks within their scheme, or to differences among climate models.

We study aerosol effects in equilibrium coupled aerosol-climate experiments, for 1990's and 1890's conditions. In order to compare the aerosol effects, we perform a series of experiments, beginning with direct effects (DE) only, adding aerosol indirect effects (IE) on liquid clouds and finally BC-albedo (BAE) effects. Semi-direct effects are included in all experiments, along with DE. Aerosol impacts may differ if GHG's change concurrently. Therefore we perform one set of experiments with only aerosol changes and a second with both GHG and aerosol changes.

There have been relatively few studies that include fully coupled aerosol-climate effects. Rotstayn and Penner (2001) simulated aerosol DE and IE using both fixed sea surface temperatures (SSTs) and equilibrium climate experiments and compared radiative forcing 
measures for these. Jacobson (2002) used a coupled aerosol-climate model and compared warming effects of carbonaceous aerosols with that of GHG's. Feichter et al. (2004) performed coupled aerosol DE and IE in equilibrium climate experiments and found the combined aerosol and GHG effects were reduced relative to the sum of the individual effects. In a BC-climate study, Wang (2004) found that BC has a significant effect on the model's hydrologic cycle, generally slowing the hydrologic cycle and increasing low-level clouds. Jones et al (2007) compared climate impacts from $\mathrm{CO}_{2}$ with aerosol DE and IE. They found that anthropogenic BC and sulfate have comparable large high-latitude NH temperature response patterns, while $\mathrm{CO}_{2}$ impacts high latitude temperatures in both hemispheres, and biomass burning aerosols cause a more uniform temperature response.

Since aerosols may have important effects on Arctic climate, we will include extra focus on this region. In a previous model study, Shindell (2007) showed that aerosol DE and IE on Arctic SAT are largest during winter, and suggested that this comes from non-local forcings. The study used the offline IE parameterization of Hansen et al. (2007) and did not include the effects of $\mathrm{BC}$ on snow albedo. We revisit the climate effects of aerosols within the Arctic using our fully coupled aerosol simulation.

\section{Model Description}

We use GISS ModelE (Schmidt et al., 2006) coupled to the aerosol simulation of sulfate, black and organic carbon and sea-salt (Koch et al. 2006, 2007). Model vertical resolution is 20 levels, horizontal resolution is $4^{\circ} \times 5^{\circ}$. Tracer mass, humidity and heat are transported using the quadratic upstream scheme. Tracer dry deposition uses a resistance-in-series scheme; 
settling of aerosols is included. The aerosols, assumed to be externally mixed, affect model radiation as described in Section 3b. Model cloud types are convective and stratiform, with a prognostic treatment of stratiform cloud water (Del Genio et al., 1996; Del Genio et al., 2005a). Aqueous sulfur chemistry and soluble species deposition are tightly coupled to the GISS model cloud schemes. Aerosol indirect effects on clouds are described in Section 3c.

Simulated aerosol and precursor species include sulfate, sulfur dioxide $\left(\mathrm{SO}_{2}\right)$, hydrogen peroxide, dimethylsulfide, organic matter (OM) and black carbon (BC). Organic matter $(\mathrm{OM})$ is assumed to include organic carbon (OC) and associated compounds, such that $\mathrm{OM}=1.3 \mathrm{xOC}$. Dry and aqueous sulfur chemistry are described in Koch et al. (2006) and Koch et al. (1999). Sulfate and sea-salt are assumed to be fully soluble within cloud droplets. Non-biomass burning BC and $\mathrm{OM}$ are assumed to be emitted as insoluble, aging to soluble with e-fold lifetimes of 1 and 0.5 days, respectively, to approximate the effect of mixing with soluble components. Biomass burning BC and OM are assumed to have constant solubilities of $60 \%$ and $80 \%$, respectively.

The model tracks aerosols after they are dry and wet deposited on and in snow. Snowpack resolution is 1-3 layers depending on snow thickness. Aerosols in snow are assumed to be fully soluble, so they are carried and removed by snow melt, and may be carried to the base of the pack to be refrozen or to enter the ground layer below along with the water. We note that $\mathrm{BC}$ solubility in snow is uncertain but probably accumulates somewhat at the snow surface (e.g. Flanner et al., 2007), a feature we will incorporate in future studies.

We use aerosol emissions for mid-1990's and late 1890's. Sulfur emissions for 1995 anthropogenic sources are from the Emission Database for Global Atmospheric Research (EDGAR) v3.2 1995. Black and organic carbon anthropogenic emissions for the year 1996 are from 
Bond et al. (2004). Biomass burning emissions for $\mathrm{BC}, \mathrm{OC}$ and $\mathrm{SO}_{2}$ are based on the Global Fire Emissions Database (GFED v1) (see Koch et al., 2007). Natural $\mathrm{SO}_{2}$ volcanic and DMS sources and natural OM emissions from terpenes are described in Koch et al. (2006). All emissions are injected into the lowest model level except for biomass burning, which is distributed across the model boundary layer (i.e. the level to which dry convection mixes) and volcanic emissions which are specified by the AeroCom model intercomparison project (http://nansen.ipsl.jussieu.fr/AEROCOM/).

Emissions for $1890 \mathrm{SO}_{2}$ from energy-generation are from van Aardenne et al. (2001). We derived our own 1890 carbonaceous aerosol emissions as follows. Carbonaceous fossil fuel emissions were assumed to come from coal combustion. BC coal emissions are derived from the historic sulfur inventory of Lefohn et al. (1999), assuming 0.14 Tg BC/Tg S; OC emissions are assumed to be a factor of 4 larger than BC. Biofuel burning history is taken from van Aardenne et al. (2001) $\mathrm{SO}_{2}$ biofuel; the $\mathrm{BC}$ and $\mathrm{OC}$ biofuel emission is calculated using present-day ratios of biofuel BC and OC (from Bond et al., 2004) relative to the 1990 biofuel $\mathrm{SO}_{2}$ emissions from van Aardenne et al. (2001). The resulting 1890 carbonaceous emissions are similar to those derived more precisely by Bond et al. (2007). For 1890 energy-production BC emission is $1.7 \mathrm{Tg}$ yr-1 compared with Bond et al. (2007)

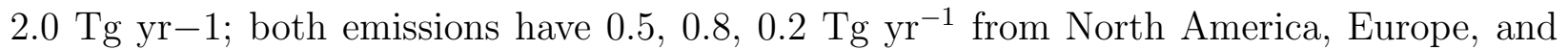
southeast Asia, respectively. Total OC emission is $4.7{\mathrm{Tg} \mathrm{yr}^{-1}}^{-1}(0.9,1.6$, and $0.8 \mathrm{Tg} \mathrm{yr}-1$ from North America, Europe, southeast Asia) compared with Bond et al. (2007) $5.8 \mathrm{Tg} \mathrm{yr}^{-1}$ (1.8, 1.8, $0.5 \mathrm{~T} \mathrm{yr}^{-1}$ from North America, Europe, and southeast Asia). Little is known of historical biomass burning, so we assume the 1890 burning emissions were 0.5 present-day in tropical burning and African savanna regions but unchanged elsewhere. Natural emissions 
are assumed unchanged. Net emission for the species are in Table 1.

Model $\mathrm{SO}_{2}$ and aerosols for 1995 are compared with observations in Koch et al. (2006, 2007). Model concentrations generally agree within a factor of two of surface concentration observations.

The model ocean is a $65 \mathrm{~m}$ slab Qflux mixed layer. The mixed layer permits ocean response to atmospheric temperature change by adjusting energetically, rather than including the full ocean dynamics of a deep ocean. Schmidt et al. (2006) provides details of ModelE Qflux treatment. The model performances of fully dynamic and slab ocean are compared in Hansen et al. $(2005,2007)$. The climate sensitivity, $2.7^{\circ} \mathrm{C}$ for doubled $\mathrm{CO}_{2}$ is the same for both ocean types, however the southern hemisphere warming is stronger for the Qflux slab ocean since it does not allow for deep ocean mixing and surface temperature moderation (Hansen et al., 2007). For the Qflux control simulations, the model net heat flux of energy into the ocean is adjusted to be close to zero. A five-year simulation is then performed, saving ocean horizontal heat transports and temperature at the base of the maximum mixed layer depth. These are applied as boundary conditions for the climate runs. The climate simulations are permitted to run until a steady SAT is achieved, and required 13-24 years. The following 10 years are analyzed. During these years the global mean SAT oscillates within $0.1^{\circ} \mathrm{C}$; in the Arctic the mean SAT is also apparently steady but has larger variability, typically within $1.0^{\circ} \mathrm{C}$.

We perform Qflux experimental pairs: control (1890) and perturbation (1995), listed in Table 2. Each successive pair includes an additional effect. The first set has only aerosol changes. The second set includes long-lived GHG changes, as well as changes in solar and ozone forcings. A third set of simulations used 1876-85 prescribed SSTs and 1890 GHG's for 
purposes of calculating alternative aerosol forcing metrics.

\section{Aerosol Effects}

a. Direct Effects (DE)

For direct radiative effects (DE), the aerosols are assumed to be externally mixed and the forcing calculations are based on Mie code embedded in the GCM (Schmidt et al., 2006). Effective radii (dry) are assumed to be $0.15,0.2$ and $0.09 \mu \mathrm{m}$ for sulfate, organic carbon $(\mathrm{OM})$ and black carbon $(\mathrm{BC})$, respectively. These values are smaller than in our previous studies (e.g. Koch et al., 2007) in order to improve model comparison with retrieved Angstrom Exponent (Liu et al., 2006), AERONET aerosol optical depth (AOD) and aerosol absorption optical depth. Otherwise, the aerosol optical properties are as described in Koch et al. (2007).

Global annual aerosol burden, AOD, instantaneous radiative forcing at the top of the atmosphere (TOA) and at the surface for 1995 and 1890 are in Table 1. These are given for the DE-only simulation, however these results differ little among simulations. Annual mean AOD distributions for BC and sulfate are shown in Figure 1. Sulfate AOD increases across the northern hemisphere (NH) between 1890 and 1995. BC also increases across most of the NH, however in England and in eastern United States, BC emissions and concentrations were larger in 1890. This negative change in BC is larger near the surface, as discussed below. Assumed biomass burning changes have also increased the southern hemisphere (SH) $\mathrm{BC}$ burden. OC changes are roughly similar to those for BC. Global mean sulfate and BC 
AODs approximately double over the century, however OM forcing increases more modestly due to substantial and residential burning and natural sources in 1890.

The aerosol direct radiative forcing, $\mathrm{F}_{D}$, is calculated from the difference between the TOA radiative flux with and without aerosols at each model timestep (averaged for the month or year). We use the slab-ocean experiments for the calculation, however the result is similar for the fixed SST ocean simulations (see Section 5). The change in $\mathrm{F}_{D}$ from 1890 to 1995, the anthropogenic $\mathrm{F}_{D}$ or $\mathrm{AF}_{D}$, is $-0.1 \mathrm{~W} \mathrm{~m}^{-2}$ (Table 1 , Figure $2 \mathrm{a}$ ). Table 1 also provides aerosol clear sky $\mathrm{F}_{D}$ (last column), calculated by weighting $\mathrm{F}_{D}$ by the clear-sky fraction at each time step. The clear sky $\mathrm{AF}_{D}$ is $-0.3 \mathrm{~W} \mathrm{~m}^{-2}$ and is more negative than all-sky $\mathrm{AF}_{D}$, because the scattering aerosol effect is greater when clouds are not the dominating source of scatter. Furthermore, BC positive forcing is larger when these absorbing aerosols overlie bright clouds (Haywood and Ramaswamy, 1998; Penner et al., 1998), since they reduce the albedo. This more negative clear-sky forcing also occurs in other global aerosol models (Schulz et al., 2006). The $\mathrm{AF}_{D}$ at the model surface (Table 1, Figure 2b) differs from the TOA forcing primarily because absorbing aerosols have a positive TOA forcing but negative surface forcing. The difference between TOA and surface forcing, or the atmospheric column forcing, doubles over the century from 0.8 to $1.6 \mathrm{Wm}^{-2}$ (Figure 2c). The regions of strongest TOA negative forcing change (Figure 2a) also generally have strongest column absorption (Figure 2c), e.g. the mid-latitudes of the NH. 


\section{b. Indirect Effect (IE)}

Our aerosol indirect effect (IE) treatment includes the effects of aerosols on liquid-phase stratus and convective clouds. The impact is primarily on low-level stratus clouds, since these tend to be liquid and are in the vicinity of large aerosol concentrations. We use a semiprognostic relation between cloud droplet number concentration (CDNC) and aerosol number (converted from aerosol mass), based on observations (separate equations for convective and stratus clouds). For stratus clouds, CDNC depends also on cloud cover and turbulence where cloud top entrainment stability is used as a proxy for in-cloud turbulence (Menon and Rotstayn, 2006; and Menon et al. 2008). The autoconversion rate is based on a cloud droplet threshold size ( $\sim 14 \mu \mathrm{m}$; Menon and Rotstayn, 2006). The IE simulation, in a similar version of the model, has been compared with several cloud microphysical variables from satellites (MODIS, AMSR-E, CERES). Compared to observational constraints, the indirect effect was

slightly over-estimated for the Atlantic Ocean region (Menon et al. 2008) and thus, our estimates may be considered as an upper limit.

Figure 3 shows IE-related diagnostic changes from 1890 to 1995, where the top row is for the IE (DI-D) experiments and the bottom for Ig (DIg-Dg; including GHG changes). One measure of the IE is the change in cloud forcing (CF) for different aerosol amounts. We define $\mathrm{CF}$ as the change in net, shortwave (SW) plus longwave (LW), TOA radiative flux, calculated as the instantaneous flux difference with and without clouds, then averaged monthly and annually. The "anthropogenic" change in cloud forcing from 1890 to 1995, $\mathrm{ACF}_{I}$, is shown in Figure $3 \mathrm{a}, \mathrm{f}$. The $\mathrm{ACF}_{I}$ is generally negative in polluted regions where the aerosol load is greatest. The CDNC (Figure 3e, $\mathrm{j}$ ) and cloud optical depth (COD; Figure 
3b, g) also increase in polluted regions. The cloud liquid water path (LWP; Figure 3c, h) increases and precipitation decreases (not shown) over most land areas. Generally, the LWP increases/decreases for low/high latitudes from increased aerosols, and decreases/increases for low/high latitudes from GHG increase (not shown). A similar result was found by Jones et al (2007), who argued that the LWP changes respond more to thermodynamic changes, such as the shift from ice to liquid phase clouds in a warming polar climate, rather than microphysical (IE) changes. As expected, low level cloud cover (CC; Figure 3d, i) increases overall.

The $\mathrm{ACF}_{I}$ depends on changes in both CC and LWP. Table 4 shows ACF for runs D, DI and $\mathrm{I}$, where $\mathrm{ACF}_{I}$ is the difference between $\mathrm{ACF}_{D I}$ and $\mathrm{ACF}_{D} \cdot \mathrm{ACF}_{D}$ is positive overall, especially over oceanic regions. This is because the CF for 1995 over oceans consists of the difference between dark aerosols over bright clouds (scene with cloud) and bright aerosols over dark ocean (scene without clouds), leading to a relatively positive CF compared with the pre-industrial case. These effects are removed for the IE, and $\mathrm{ACF}_{I}=-1.2 \mathrm{Wm}^{-2}$ or $\mathrm{ACF}_{I g}=-1.3 \mathrm{Wm}^{-2}$ (Figure 3a, f). The global IE cloud forcing change thus does not change very much with GHG changes. As for the DE, these calculations were done with slab ocean, however the results are similar for fixed SST, as discussed further in Section 5.

The $\mathrm{ACF}_{I}$ is negative in most regions and is maximum over Asia, where aerosol amount has increased most. The decrease in LWP near the Arctic apparently causes the positive $\mathrm{ACF}_{I}$ there, as well as in the southern oceans. This is not the longwave cloud effect described by Lubin and Vogelmann (2006) and Garrett and Zhao (2006). The positive Arctic $\mathrm{ACF}_{I}$ is in the shortwave is maximum in summertime, especially beyond the periphery of the ice sheet where cloud changes have a larger impact on radiation. 
c. BC-albedo Effect (BAE)

We have implemented a new model scheme for snow albedo dependence upon BC snow concentration. We first compared model BC air and snow concentrations and removal from the 1995 simulation with available recent Arctic observations. Removal is from dry and wet deposition, and the wet removal can be by either liquid or frozen precipitation. There is uncertainty in how much $\mathrm{BC}$ is removed by frozen precipitation. we found that $12 \%$ removal by ice, relative to liquid, gives optimal agreement with observations. This fraction is confirmed by observations during winter in Jungfraujoch by Cozic et al. (2007) who measured $60 \%$ removal of $\mathrm{BC}$ by liquid phase clouds and $5-10 \%$ removal by mixed phase clouds, or $8-17 \%$ removal by mixed phase relative to liquid phase; our $12 \%$ assumption falls mid-range of these observations.

As shown in Koch et al. (2007), model BC surface concentrations agree to within $50 \%$ in Alaska (Denali and Barrow) and are underestimated but within a factor of two at Spitsbergen. Figure 4 shows three deposition features, observed and modeled. Figure 4a and b show deposited BC (ng/g) for annual average and the winter-spring months. The November-April time-period is selected because most observations are from these months. BC transport to and removal within the Arctic are largest during this time. BC snow concentration data within the circles (Figure 4a,b) are 1990's data cited within Flanner et al. (2007, Table 2). The model agreement with observations is within $10 \%$ in Greenland and Halifax, but model $\mathrm{BC}$ deposition is a factor of two too large in the Arctic Ocean (76N, 165E) and a factor of 10 too small in the Alps.

The fraction of particle removal by dry versus wet deposition in the Arctic is quite 
uncertain. Davidson et al. (1985) compared wet and dry removal at Dye 3 in Greenland. They estimated about $25 \%$ dry deposition for soluble species for annual average, but about $50 \%$ during the dryer spring months. The model agrees well at this location for the annual average and generally with the seasonality. Harder et al. (1996, e.g. Figure 2) showed that in Antarctica, wet deposition dominates if snow accumulation rate exceeds $15-20 \mathrm{~g}$ $\mathrm{cm}^{-2} \mathrm{yr}^{-1}$. Since Arctic accumulation is observed to be within this range, about $16 \mathrm{~g}$ $\mathrm{cm}^{-2} \mathrm{yr}^{-1}$ (Warren et al., 1999), we expect that dry deposition and wet deposition should be roughly equal. Model precipitation in the Arctic is about $13 \mathrm{~g} \mathrm{~cm}^{-2} \mathrm{yr}^{-1}$, somewhat less than observed. Model Arctic BC removal is generally more wet than dry (Figure 4c), but dry and wet deposition are roughly equal during the dryer winter months (Figure 4d). Another constraint is the scavenging ratio, or the fraction of aerosol within precipitation relative to that within air (Figure 4e). Davidson et al. (1985) observed values of 100-200 for soluble species at Dye 3; Noone and Clarke (1988) measured about 100 in Abisko, Sweden. The model scavenging ratio agrees with the latter, and is smaller but within a factor of two at Dye 3.

The change in albedo as a function of BC snow concentration is taken from Warren and Wiscombe (1985; WW85, Figure 2). We use the 'spectrally averaged' albedo reduction in the figure because the model has only 1 visible snow-albedo band (300-770 nm); this band and the first near infrared $(770-860 \mathrm{~nm})$ are both reduced. WW85 provides albedo reduction for both fresh (0.1 mm grain radius) and old melting (1 $\mathrm{mm}$ grain size) snow. We derive snow grain size as a function of model SAT and snow age from Marshall (1989, illustrated in Figure 3.4 with fortran code in Appendix B). We interpolate linearly between the 0.1 and $1 \mathrm{~mm}$ snow grain size curves (in WW85 Figure 2) to determine the albedo depression from 
BC snow concentration. BC concentrations in the top layer of land-snow and snow on sea ice are used to determine the albedo reduction.

We measure the BAE radiative forcing $\mathrm{F}_{B}$ by taking the instantaneous difference between the TOA radiative flux with and without the BC-albedo effect for each radiation time-step (averaged monthly and annually). For this calculation we used the fixed SST experiments. The global average $1995 \mathrm{~F}_{B}$ is $0.03 \mathrm{Wm}^{-2}$, and difference between 1995 and $1890, \mathrm{AF}_{B}$ is

$0.01 \mathrm{Wm}^{-2}$ (Figure 2d). The Arctic $\mathrm{AF}_{B}$ is $0.03 \mathrm{Wm}^{-2}$. These forcing changes are especially large near the major source region of south-central Eurasia. Snow cover within this region varies from $30 \%$ in winter to $2 \%$ in summer. Peak $\mathrm{AF}_{B}$ is over $4 \mathrm{Wm}^{-2}$ in springtime when snow cover and solar angle combine to provide maximum forcing. The model of Flanner et al. (2007) also had maximum forcing in this region. Like the BC AOD change (Figure 1c), the $\mathrm{AF}_{B}$ near Europe and eastern United States is negative since BC emissions were larger in 1890 than in 1995.

\section{Climate Responses}

We now consider aerosol effects on climate in the Qflux experiments, including changes in surface temperature, clouds and other hydrologic features, snow and ice cover, dynamics and radiative flux. We also seek correlations among these. 


\section{a. Surface Air Temperature}

Figure 5a, b, and c show the D, DI and DIB experiments' effects on SAT. Although the aerosol-climate effects may not be exactly linear, i.e. a given effect may differ when combined with other effects, we are better able to see them if we take the difference between successive experiments. Furthermore, Jones et al. (2007) demonstrated that aerosol DE and IE on SAT and precipitation are approximately additive in their model. Figure 5 d shows the IE on SAT (difference between panels a and b) and Figure 5e shows the BAE on SAT (difference between panels c and b).

The aerosol effects are clearest in the experiments with fixed GHG (top row). The DE lowers SAT by $-0.15^{\circ} \mathrm{C}$ (Figure 5a), with largest decreases over Eurasia. Increased temperature over Antarctica is due to increased SH biomass burning sending absorbing aerosols over the bright polar region. The IE lowers the temperature by another $-1.0^{\circ} \mathrm{C}$ (Figure 5d) and cooling increases with latitude, especially in the NH. The BAE raises the SAT slightly relative to the experiment without BAE, $0.18^{\circ} \mathrm{C}$ (Figure $5 \mathrm{e}$ ). This effect is also largest in polar regions, but cooling occurs over Europe due to the smaller 1995 BC in this region.

The GHG effect dominates the net SAT change (bottom row of Figure 5). We cannot distinguish the DE from the GHG increase (Figure 5f) since we have allowed both to change together. Nevertheless the aerosol impact on SAT is evident over the northern oceans. For these experiments the IE (Figure 5i) and BAE (Figure 5j) on SAT are weaker than with fixed GHG.

Although we do not expect equilibrium Qflux slab ocean experiments that do not include 
all relevant forcings to reproduce the temperature changes perfectly, we may compare with the observed SAT change from 1890 to 2000 (Figure 5k). The simulation with all three aerosol effects and GHG changes (Figure 5h) agrees best with the observed changes. Run DIBg average SAT increase is larger $(+0.9$ instead of $+0.6 \mathrm{C})$, since our experiment is run to equilibrium; note also that the polar regions lack observational constraint, where model temperature increase is largest. The biggest discrepancy is in the southern oceans, where deep-ocean circulation would moderate the temperature change, and ice-melt in the equilibrium experiment would exceed observations. However even in the historical transient GISS model simulation that included a deep ocean (Hansen et al., 2007), the SAT increase is more than observed in the southern oceans. Also, as in Hansen et al. (2007) model simulations, we lack sufficient warming over Europe; this was attributed to excessive sulfate increase in that region. The model also fails to produce the observed cooling trends in southeast Asia, southern Africa and South America. These are regions where present-day model aerosol loads, and possibly emissions, may be underestimated. Compared with recent aerosol surface concentrations in southeast Asia, the model is generally too small by more than a factor of 2 (Koch et al., 2007). The model African and South American regions may also have underestimated biomass burning aerosols that would cool the underlying SAT. Biomass burning trends are highly uncertain and our assumptions of their changes during the century are quite simple (see Section 2). Apart from these discrepancies, many of the observed patterns are reproduced in the model, e.g. with larger warming over continents and at high latitudes, and cooling south of Greenland.

The average Arctic (north of 60N) SAT changes are given in brackets in Figure 5. Typically the Arctic SAT change is approximately double the global average change. Seasonalities 
of these changes are in Figure 6a. The maximum impacts on SAT occur during winter-spring.

\section{b. Hydrologic Effects}

Climate model clouds typically shift when temperatures change. The GISS ModelE clouds have nearly neutral global climate feedback with doubled $\mathrm{CO}_{2}$ (Schmidt et al., 2006), however this is due to regionally compensating changes. Warmer temperatures increase lowlevel water vapor, and as this is transported in upwelling regimes to the upper troposphere, relative humidity and cloudiness increase aloft but decrease at low levels. Thus, at lowmid latitudes low level cloudiness generally decreases/increases in response to warmer/cooler temperatures (Del Genio et al., 2005a, 2005b; Yao and Del Genio, 1999). Such cloud changes provide positive temperature feedbacks; these feedbacks are balanced by negative cloud feedbacks in the polar regions for doubled $\mathrm{CO}_{2}$ (Yao and Del Genio, 1999). Figure 7 shows the percent change in cloud cover (CC) for the experiment pairs. The net cloud change is dominated by low-mid level clouds.

Comparison of cloud (Figure 7) with SAT (Figure 5) changes suggests correlation between these in many regions. The DE simulations without GHG changes have increased clouds (Figure 7a) over the same mid-latitude NH regions that are cooler (Figure 5a); the loss of clouds near Greenland may explain the warming there. The simulation with IE has increased low-level clouds over mid-latitudes especially in the NH (Figure 7b, 7d), consistent with cooling of the mid-latitudes of the NH (Figure 5b, 5d). Spatial cross-correlations (dotproduct by model grid-cell) between cloud and SAT changes are in Table 3. Correlation between SAT and cloud cover changes is -0.22 for DE and -0.33 for IE. For low cloud cover 
these are larger, -0.34 and -0.53 . The IE thus increases correlation between CC and SAT.

GHG warming decreases CC over mid-latitudes of both hemispheres (Figure 7f). The IE increases CC by $0.5 \%$ with or without GHG increase (Figure $7 \mathrm{~d}, \mathrm{i}$ ). The SAT and CC changes with IE and increased GHG (Figure 5i, 7i) are more variable spatially than without GHG increases, since aerosols and GHG have opposing influences on CC. Nevertheless, the correlation between CC and SAT changes remains: cooler temperatures over the northern oceans correlate with increases in CC; warmer temperatures in the Pacific Asian-outflow region correlate with decreased CC there.

The BAE does not produce significant net CC changes. Nevertheless, the regional SAT changes typically correlate with CC changes. For example, cooling over Europe and the United States (Figure 5e) is associated with increased clouds (Figure 7e). Anti-correlation between CC and SAT changes within the Arctic are especially large for the DIBg run (Table 3, correlation of -0.4). Here there are increased clouds and reduced temperatures over northern Europe, decreased clouds and warmer temperatures over the northern oceans.

We compare these cloud changes with those in similar GISS model simulations. Hansen et al. (2005) prescribed a $-1.0 \mathrm{Wm}^{-2}$ IE forcing, by making the CC change dependent upon offline aerosol mass fields, and had $1.1 \%$ increased CC for fixed SST experiments. In the same model but in a transient 1880 to 2000 coupled-ocean experiment, the CC increased by $0.8 \%$ (Hansen et al., 2007). Their parameterized IE caused larger CC changes than our on-line prognostic IE.

Global mean precipitation and evaporation decrease/increase in response to decreased/increased temperature changes in the experiments. Precipitation and evaporation both decrease by $-0.03 \mathrm{~mm} \mathrm{~d}^{-1}$ from the DE (from 1890 to 1995) if GHG is fixed. They increase by 0.10 
$\mathrm{mm} \mathrm{d}^{-1}$ from the DE if GHG increases. Adding IE decreases precipitation and evaporation by $-0.07 \mathrm{~mm} / \mathrm{d}$ in both experimental pairs. Thus the aerosol effects nearly cancel the GHG effects on the global mean hydrologic system in our experiments. This is also seen in the full-ocean 20th century GISS model simulation (Romanou et al., 2007). The BAE has negligible global average effects on precipitation and evaporation.

The seasonality of Arctic CC changes is shown in Figure 6b. The largest change is increased $\mathrm{CC}$ due to the IE (without GHG increase). This case had $+0.7 \%$ cloud cover, maximum during summertime. Water vapor also decreased, primarily during summer.

\section{c. Snow/Ice/Albedo}

Aerosols impact snow and ice cover and therefore ground albedo in two ways. Their cooling effect on surface temperatures promotes ice and snow cover, raising ground albedo as the dark ground is covered with bright ice/snow. However, BC deposition darkens the snow, reduces surface albedo, promotes melting of snow which further decreases albedo. Figure 8 shows aerosol effects on snow/ice cover; impacts on ground albedo (not shown) are similar in sign and distribution.

Global snow/ice cover in the GISS model is about 10\%. Thus, without GHG changes (Figure 8 top row), cooling from the aerosol DE increases snow/ice cover by about $1 \%$ of the original cover (Figure 8a). The IE cooling increases snow/ice by about 10\% (Figure 8b, d) and the BAE decreases snow/ice cover by about 3\% (Figure 8c,e), relative to the original cover. In western Europe the snow cover increases because of decreased BC emissions. The changes in ice/snow are anti-correlated with SAT changes, with cross-correlations ranging 
from -0.4 to -0.5 (Table 3 ).

With GHG increase (Figure 8 bottom), the warmer temperatures promote melting of snow/ice and therefore decrease albedo. The IE again increases ice/snow cover (Figure 8i), but the effect is smaller a factor of two compared to the case without GHG change (Figure $8 \mathrm{i}$ vs $8 \mathrm{~d}$ ). Thus the combined aerosol IE and GHG effects are smaller than the sum of their individual effects. The correlation between snow/ice cover and SAT changes are also smaller if GHG's increase (about -0.3 instead of -0.4 to -0.5 ). With the GHG increase, the change in ice/snow/albedo from the BC-albedo effect is negligible globally (Figure 8j). However albedo/ice/snow are reduced in northwestern North America; they increase in eastern North America and much of Eurasia. Note the spatial correlation among these changes (Figure 8i, j) and cloud changes (Figures 7i, j) and SAT changes (Figure 5i,j). In general, the cryospheric and cloud cover changes are positively correlated (Table 3) with cross-correlations from 0.130.35, and are generally larger in the Arctic.

The smaller impact of BAE on snow/ice with increased GHG's results partly from increased BC removal rate from 1890 to 1990, so that more BC is removed near source regions and less is transported to the Arctic. The change from cooler to warmer climate causes a shift from ice to liquid phase clouds in the model: globally, GHG warming causes $1 \%$ increase in liquid and 1\% decrease in ice phase clouds between 1890 and 1995. These shifts are reversed with fixed GHG's as the climate is cooling. (A similar shift occurs in the Arctic as for the global average.) Since we assume that liquid clouds remove BC more effectively than ice clouds, the BC load and Arctic deposition increase less in the simulation with GHG changes (Figure 9b versus Figure 9a). The smaller increase in $\mathrm{BC}$ in the Arctic reduces the impact of $\mathrm{BC}$ on snow/ice albedo. 
Seasonality of Arctic snow/ice cover change is shown in Figure 6c. Impacts are maximum during summer/fall. The largest effect is from the IE (without GHG change). Crosscorrelation of snow/ice and cloud cover is 0.44 (Table 3). The IE impact on snow/ice cover persists into the winter months. However, again these effects (Figure 6c) are clearly not in phase with the SAT seasonality (Figure 6a). As we will discuss further below, the SAT impacts may have delayed seasonal effect.

\section{d. Dynamics}

Aerosols also impact atmospheric circulation patterns. Figure 10 shows the changes in sea level pressure (SLP) and Figure 11 the effects on zonal stream function. Some changes in $\mathrm{SLP} /$ circulation seem to be associated with warming/cooling of the overall climate. Many models (e.g. Hansen et al., 2007; Shindell et al., 1999; Proshutinsky and Johnson, 1997; $\mathrm{Hu}$ and Wu, 2004; Sigmund et al., 2004) but not all (see discussion in Rind et al., 2005) have a tendency for positive Arctic or North Atlantic Oscillation (AO/NAO) and decreased Arctic SLP with warmer climate. Various mechanisms may be responsible (Rind et al., 2005), including warming of the tropics, reduction of equator-pole temperature gradient and change in refraction of planetary waves leading to a positive AO configuration. Consistent with this, our SAT (Figure 5) and SLP (Figure 10) changes are generally anti-correlated, especially in the NH, with cross correlations given in Table 3. (The DE has negative crosscorrelation in the $\mathrm{NH}$, although positive in the $\mathrm{SH}$.) Aerosol cooling from DE and IE have increased Arctic SLP (Figure 10a, b, d) and reduced poleward low-level meridional velocity (Figure 11a) Warming due to increased GHG reduces Arctic SLP (Figure 10f) and enhances 
poleward velocity (Figure 11f).

However the BAE, a generally warming effect, has overall increased Arctic SLP (Figure 10e, j) especially during wintertime (Figure 6d, red curves), and the Arctic cross-correlation of SLP with SAT (Table 3) is small or even positive (for increased GHG's). Negative correlation does occur for BAE, just south of the Arctic, especially over the northern oceans. Also in the SH, the SLP and SAT are sometimes positively correlated over Antarctica, but negatively correlated over the oceans, e.g. for DI, DIg, Dg. These support an ocean-temperature driven mechanism for the SAT-SLP anti-correlation tendency.

The Arctic seasonality of SLP changes (Figure 6d) are largest during winter, generally anti-correlating with the SAT changes, except for the BAE with its positive SAT-SLP correlation. This suggests larger dynamical effects during winter.

\section{Discussion}

Aerosol radiative forcing is often used to infer expected effects on temperature. Here we consider definitions of aerosol radiative forcing or flux change used by us and compare with estimates from other studies. We also use the SW and LW radiative flux changes in the Arctic as a tool to understand the aerosol climate impacts there.

We reported the 1890 to 1995 change of the TOA radiative flux change with and without the presence of aerosol DE (Table 1), clouds (the ACF, Table 4), and the BC effect on snow albedo (Figure 2d). A possible difficulty with these diagnostics is that they involve taking the difference with the same atmosphere but without the forcing agent, an artificial state.

Several alternative definitions of radiative forcing have been explored in detail by Hansen 
et al. (2005). One measure that appears to provide an accurate indication of temperature impact and is relatively easy to calculate is the TOA radiative flux changes due to a changing forcing agent with SST held constant, $\mathrm{F}_{s}$. This is especially useful for the second IE since the 'forcing' also includes a change in the forcing agent, cloud amount. This approach was first proposed and called "quasi-forcing" by Rotstayn and Penner (2001). It was altered by Hansen et al (2005) by the addition of the (typically small) perturbation to the SAT, normalized by the model climate sensitivity, for the fixed SST experiment. Rotstayn and Penner (2001) compared various estimates of aerosol forcing, by carefully defining experiments that isolated direct, first and second indirect aerosol effects. They demonstrated that quasi-forcing provides a good estimate of pure forcing, where pure forcing was the difference in TOA radiative flux using present-day versus pre-industrial forcing agents. Such a calculation could only be performed for DE and first IE. They also showed that the change in net TOA irradiance is nearly the same as the change in cloud forcing, for the first and second indirect effects, so that clear-sky feedbacks are small.

We consider similar questions here, although our experiments were not designed to isolate radiative flux changes apart from climate changes and atmospheric feedbacks. We note that, similar to Rotstayn and Penner (2001), the cloud forcing change $\mathrm{ACF}_{I}$ is nearly identical to the change in TOA radiative flux $\mathrm{AF}_{I}$ (Table 4), $-1.2 \mathrm{Wm}^{-2}$ for our fixed SST experiments. The geographical distributions are similar, although the magnitude of $\mathrm{AF}_{I}$ in some regions is smaller, e.g. the positive forcing changes in the polar regions and the negative forcing changes over the oceans. Furthermore, approximately the same $\mathrm{ACF}_{I}$ results from the Qflux experiments, suggesting that global climate feedbacks are small. For the Qflux experiment with increasing GHG's, the $\mathrm{ACF}_{I}$ is only slightly larger, $-1.3 \mathrm{Wm}^{-2}$. 
Note however, that the IE must be isolated from the DE in order to achieve this equivalency in forcing. Such isolation is artificial, because in the real world the IE does not occur without the DE and the experiments with both DE and IE are most realistic (the central section of Table 4). However, for this case, the TOA flux change $\mathrm{AF}_{D I},-1.4 \mathrm{Wm}^{-2}$, is much greater than the $\mathrm{ACF}_{D I},-0.6 \mathrm{Wm}^{-2}$. As discussed above, in our model diagnostics the $\mathrm{CF}_{D I}$ includes the artificial effect of taking the difference between cloudy conditions and bright aerosol (for present day), so that the $\mathrm{ACF}_{D I}$ is underestimated. Thus the TOA flux calculation is more realistic. This suggests that CF calculations of the IE must be used carefully, either by isolating the IE parameters, as Rotstayn and Penner (2001) did, or by subtracting the $\mathrm{CF}_{D}$ as we do. Alternatively, the cloud-free condition could also be diagnosed using an aerosol-free atmosphere.

Now we compare our IE forcing with some other recent studies. Our $\mathrm{ACF}_{D I}$ value without increasing GHG, $-0.62 \mathrm{Wm}^{-2}$, is very similar to that obtained by Menon and Del Genio (2007) (-0.65 $\mathrm{Wm}^{-2}$ ) with a similar model version. Takemura et al. (2005) estimated $-0.94 \mathrm{Wm}^{-2}$ for first and second IE (using net flux change at TOA). IPCC (2007) made a central estimate of $-0.7 \mathrm{Wm}^{-2}$ for the albedo (first) IE only. All of these are larger than the estimates of Quaas et al. (2005) $\left(-0.53 \mathrm{Wm}^{-2}\right)$, for simulations constrained with satellite data.

In general, the TOA SW flux change spatial pattern (Figure 12) is anti-correlated with cloud changes (Figure 7). This suggests that cloud changes from the aerosol effects impact SAT especially in the shortwave.

Arctic seasonality of SW TOA forcing change (Figure 13a) is largest during summer and fall, when aerosol direct forcing $\left(\mathrm{AF}_{D}\right)$, cloud and cryospheric changes are also largest (e.g. 
Figure 6). The anti-correlation of changes in aerosol forcing and SAT seasonality in the Arctic led Shindell (2007) to conclude that the wintertime Arctic temperature effects were due to non-local aerosol forcings.

An alternative hypothesis is that local aerosol effects impact local SAT with delayed seasonality. The sign of Arctic SAT change (Figure 6a) is negatively correlated with the sign of the snow/ice cover change (Figure 6c), although the seasonality differs. Shindell (2007) noted that the DE forcing change is positive in the Arctic even as it cools SAT. However the DE increases snow/ice cover (solid blue, Figure 6c), mostly over northern Eurasia (Figure 8a) where cloud cover also increases (Figure 7a) and temperature reduction is largest (Figure 5a). The increased snow/ice cover cools ground temperature and changes longwave forcing during winter. Figure 13b shows that the LW forcing change at the tropopause is largest during winter, similar to the SAT seasonality (Figure 6a). Furthermore, the LW upward forcing change at the surface (Figure 13c) correlates with the SAT changes (Figure 6a) and with the ground temperature changes (not shown). Clear sky forcing changes (Figure 13d) and seasonal change are larger than all-sky (Figure 13b); thus these longwave forcing changes do not appear to be directly related to cloud changes. Note that the IE on longwave forcing change is negative. Our model does not have an important positive LW cloud forcing change or indirect effect forcing in the Arctic. Presumably this is because the positive LW effect (Garrett and Zhao, 2006; Lubin and Vogelmann, 2006) occurs for optically thin clouds that are difficult for our model to resolve.

In summary, we suggest that in the Arctic, the aerosol effects change the ice/snow cover during summer and fall, and these cryospheric changes persist to affect wintertime SAT change. The SAT impact may be greater during winter due to increased atmospheric bound- 
ary layer stability. Figure 14 shows zonal mean temperature changes for March and July, two months with large and small Arctic SAT changes (Figure 6a). The IE temperature impact in the Arctic is confined to the surface during March (Figure 14d) but significant cooling also occurs aloft in the summer (Figure 14i). There are also stronger vertical and meridional gradients in temperature change for the BAE in March (Figure 14e) than in July (Figure $14 j)$.

Overall, the cooling (aerosol direct and indirect) and warming (GHG and BC-albedo) seasonal effects in the Arctic are generally symmetrical in their influences on radiative forcing (Figure 13) and on SAT and snow/ice cover (Figure 6). Forcing and SAT changes, positive or negative, are largest during winter/spring; snow/ice perturbations are largest during summer/fall.

\section{Summary and conclusions}

We presented equilibrium climate experiments designed to distinguish aerosol direct, indirect and BC-albedo effects on climate, with and without concurrent GHG changes, over the 20th century.

We found that the global cooling from aerosol DE and $\mathrm{IE}$ is $-0.2^{\circ} \mathrm{C}$ and $-1.0{ }^{\circ} \mathrm{C}$, and the warming from the BAE is about $+0.2{ }^{\circ} \mathrm{C}$ over the 20 th century. The net aerosol effect on SAT is approximately half as large and opposite in sign to that of the long-lived GHGs.

This is similar to the result of Hansen et al. (2007); Jones et al. (2007) had somewhat smaller aerosol cooling relative to $\mathrm{CO}_{2}$ warming (ratio of aerosol/GHG SAT effect $=-0.3$ ). Our model aerosol cooling effects are larger because of positive feedbacks clouds, cryosphere 
and temperature. Cloud-cover increased by $0.1 \%$ from the DE and by $0.5 \%$ from the IE. Ground albedo increased by $0.01 \%$ from the DE, $0.4 \%$ from the IE, and $-0.1 \%$ from the BAE if GHG is constant (these changes are smaller if GHG's increase). Thus increased clouds and brighter land surface amplify the aerosol cooling effects.

We explored some of the methods of measuring aerosol IE. A common metric, ACF, is the cloud forcing change (from 1890 to 1995), where the cloud forcing is the change in TOA radiative flux with minus without cloud. Rotstayn and Penner (2001) showed that the ACF agrees with the TOA radiative flux change for the IE, for fixed SST conditions. Our analysis agreed, however only if the IE is isolated from the DE. The Rotstayn and Penner (2001) experiments were designed to isolate DE and IE. For our experiments, we had to subtract the DE CF from the DE+IE CF. This is necessary because the CF compares the flux with cloud and without cloud, but the cloud-free condition includes bright aerosols, especially for the present-day calculation. For future studies, we recommend a CF calculation that contrasts the cloudy conditions with a cloud- and aerosol- free condition to remove the aerosol contamination of the atmosphere without cloud. Our analysis also suggests that the IE forcing from a climate experiment using a Qflux ocean is not very different from the estimate using fixed SSTs. Our IE forcing, $-1.2 \mathrm{Wm}^{-2}$, and resulting SAT change are substantial.

Our model BAE also has a relatively large impact on SAT. In order to understand this and compare with other BAE studies, we consider changes in forcing, albedo and SAT in Table 5. Comparing ratios of effects helps cancel differences in emissions. A difficulty is that ice/snow cover change in turn causes a large forcing change. These responses can vary considerably among models and degree of model equilibrium. The change in albedo from 
our study is at the low end of the studies in Table 5, the radiative forcing change is also small, and the ratio of forcing to albedo is the smallest, although it is similar to Flanner et al. (2007). The change in SAT per change in albedo ranges from $-0.15^{\circ} \mathrm{C}$ per $\%$ (in Jacobson, 2004) to -1.5 (in our study), where our study is similar to $-1.3^{\circ} \mathrm{C}$ per $\%$ of Hansen and Nazarenko (2004).

Our Arctic surface albedo (and SAT) response is smaller than Flanner et al. (2007), however our change in Arctic BC is also smaller because of the decreased European BC emissions. Yet within the Arctic, our BAE causes $0.5^{\circ} \mathrm{C}$ increased SAT and $-1.2 \%$ decrease in snow/ice cover. These would be even larger if we had used true "pre-industrial" or "prehistoric" aerosol emissions, with zero BC from all industrial activity and biofuel sources. Our results suggest that mitigating Arctic BC sources under present-day GHG conditions should increase snow/ice cover, since this is essentially the reverse of our fixed GHG experiment.

Experiments including concurrent GHG changes generally had smaller aerosol IE and BAE (we do not have an experiment isolating the direct from GHG effects). For example, the IE decreases SAT $20 \%$ and snow/ice cover $50 \%$ less if GHG also increases. Thus the warming and cooling effects add non-linearly. The BAE has very small effect on global climate if GHG also increases. Since both act to reduce the snow/ice cover, the incremental effect of the BC-albedo reduction is small, though some regional impacts are evident, such as reduced snow cover in northwestern North America (Figure 8j). The BAE, with concurrent GHG changes, may be more significant in a transient (rather than equilibrium) simulation. In contrast, global cloud changes are similar with and without GHG changes, although there are regional differences, especially in the Arctic where increasing GHG reduces the CC increase. 
In our model aerosol effects on Arctic climate are large. Our Arctic IE is quite limited because we consider only impacts on liquid clouds; we are currently developing a scheme that includes aerosol effects on ice phase clouds. Similar to other studies, we found largest aerosol effects on clouds and cryosphere during summer/fall with largest SAT effects during winter. The SAT changes correlate with ground temperature and apparently related LW forcing changes. Thus it seems that although aerosol "effects" on Arctic clouds and cryosphere, are maximum in summer-fall, their impact on SAT and sea level pressure persist into winter. We suggest that cryospheric impacts are felt more at the surface more during winter due to increased atmospheric vertical stability in that season.

Future experiments will use transient emissions and climate conditions, a fully coupled ocean, and aerosols and gases fully coupled to the GCM. This will allow study of the evolution of aerosol impacts during the past century.

\section{Acknowledgments.}

We thank Stephen Warren for assistance in development of the model BC-albedo parameterization. Support for this research is from the Clean Air Task Force, the NASA Radiation Science Program and the NASA Modeling, Analysis, and Prediction Program. 


\section{References}

Andreae, M. O., and P. Merlet, 2001: Emission of trace gases and aerosols from biomass burning, Global Biogeochemical Cycles, 15, 955-966.

Bond, T. C., D. G. Streets, K. F. Yarber, S. M. Nelson, J.-H. Woo, and Z. Klimont, 2004: A technology-based global inventory of black and organic carbon emissions from combustion, J. Geophys. Res., 109, doi:10.1029/2003JD003697.

Bond, T. C., E. Bhardwaj, R. Dong, R. Jogani, S. Jung, C. Roden, D. G. Streets, and N. M. Trautmann, 2007: Historical emissions of black and organic carbon aerosol from energy-related combustion, 1850-2000, Global Biogeochemical Cycles, 21, GB2018, doi:10.1029/2006GB002840.

Cozic, J., B. Verheggen, S. Mertes, P. Connolly, K. Bower, A. Petzold, U. Baltensperger, and E. Weingartner, 2007: Scavenging of black carbon in mixed phase clouds at the high alpine site Jungfraujoch, Atmos. Chem. Phys., 7, 1797-1807.

Davidson, C. I., S. Santhanam, R. C. Fortmann, and M. P. Olson, 1985: Atmospheric transport and deposition of trace elements onto the Greenland ice sheet, Atmos. Env., 19, 2065-2081.

Del Genio, A. D., W. Kovari, M.-S. Yao, and J. Jonas, 2005a: Cumulus microphysics and climate sensitivity. J. Clim., 18, 2376-2387, doi:10.1175/JCLI3413.1.

Del Genio, A. D., A. B. Wolf, and M.-S. Yao, 2005b: Evaluation of regional cloud feedbacks using single-column models, J. Geophys. Res., 110, D15S13, doi:10.1029/2004JD005011.

Del Genio, A. D., M. S. Yao, W. Kovari, and K. K. Lo, 1996: A prognostic cloud water parameterization for general circulation models. J. Clim., 9, 270-304.

Feichter, J., Roeckner, E., Lohmann, U., and Liepert, B., 2004: Nonlinear aspects of the 
climate response to greenhouse gas and aerosol forcing, J. Climate, 17, 23842398.

Flanner, M. G., C. S. Zender, J. T. Randerson, P. J. Rasch, 2007: Present-day climate forcing and response from black carbon in snow, J. Geophys. Res., 112, doi:10.1029/2006JD008003.

Garrett, T. J., and C. Zhao, 2006: Increased Arctic cloud longwave emissivity associated with pollution from mid-latitudes, Nature, 440, doi:10.1038.

Guenther, A., et al., 1995: A global model of natural volatile organic compound emissions, J. Geophys. Res., 100, 8873-8892.

Hansen, J. and L. Nazarenko, 2004: Soot climate forcing via snow and ice albedos, Proc. Nat. Acad. Sci., 101, 423-428, www.pnas.org/cgi/doi/10.1073/pnas.2237157100.

Hansen, J., et al., Efficacy of climate forcings, 2005: J. Geophys. Res. 110, D18104, doi:10.1029/2005JD005776.

Harder, S.L., S.G. Warren, R.J. Charlson and D.S. Covert, 1996: Filtering of air through snow as a mechanism for aerosol deposition to the Antarctic ice sheet, /it J. Geophys. Res., 101, 18729-18743, 1996.

Haywood, J.M. and V. Ramaswamy, 1998: Global sensitivity studies of the direct radiative forcing due to anthropogenic sulfate and black carbon aerosols, J. Geophys. Res., 103, 6043-6058.

Hu, z. Z., and Z. Wu, 2004: The intensification and shift of the annual North Atlantic Oscillation in a global warming scenario simulation, Tellus, Ser. A., 56, 112-124.

IPCC, The Physical Science Basis. Contribution of Working Group I to the Fourth Assessment Report of the Intergovernmental Panel on Climate Change [Solomon, S., D. Qin, M. Manning, Z. Chen, M. Marquis, K.B. Averyt, M.Tignor and H.L. Miller (eds.)]. Cambridge University Press, Cambridge, United Kingdom and New York, NY, USA, 2007. 
Jacobson, M. Z., 2002: Control of fossil-fuel particulate black carbon and organic matter, possibly the most effective method of slowing global warming, J. Geophys. Res., 107, doi:10.1029/2001JD001376.

Jacobson, M. Z., 2004: Climate response of fossil fuel and biofuel soot, accounting for soot's feedback to snow and sea ice albedo and emissivity, J. Geophys. Res., 109, doi:10.1029/2004JD004945.

Jones, A., J. M. Haywood, and O. Boucher, 2007: Aerosol forcing, climate response and climate sensitivity in the Hadley Centre climate model, J. Geophys. Res., 112, doi:10.1029/2007JD008688.

Kirchstetter, T. W., T. Novakov, and P. V. Hobbs, 2004: Evidence that the spectral dependence of light absorption by aerosols is affected by organic carbon, J. Geophys. Res., 109, D21208, doi:10.1029/2004JD004999.

Koch, D., 2001: Transport and direct radiative forcing of carbonaceous and sulfate aerosols in the GISS GCM, J. Geophys. Res., 106 (D17), 20311 - 20332.

Koch, D., G. A. Schmidt, C. Field, 2006: Sulfur, sea salt and radionuclide aerosols in GISS, ModelE, J. Geophys. Res., 111, D06206, doi:10.1029/2004JD005550.

Koch, D., T. Bond, D. Streets, N. Unger and G. R. van der Werf, 2007: Global impacts of aerosols from particular source regions and sectors, J. Geophys. Res., 112, D02205, doi:10.1029/2005JD007024.

Liu, L., A.A. Lacis, B.E. Carlson, M.I. Mishchenko, and B. Cairns, 2006: Assessing Goddard Institute for Space Studies ModelE aerosol climatology using satellite and ground-based measurements: A comparison study, J. Geophys. Res., 111, D20212, doi:10.1029/2006JD007334.

Lefohn, A. S., J. D. Husar, and R. B. Husar, 1999: Estimating historical anthropogenic global sulfur emission patterns for the period 1850-1990, Atmos. Env., 33, 3435-3444. 
Lohmann, U. and J. Feichter, 2005: Global indirect aerosol effects: a review, Atmos. Chem. Phys., 5, 715-737.

Lubin, D., and A. M. Vogelmann, 2006: A climatologically significant aerosol longwave indirect effect in the Arctic, Nature, 439, doi:10.1038.

Marshall, S. E., A physical parameterization of snow albedo for use in climate models, PhD Thesis, Cooperative Thesis for the University of Washington, National Center for Atmospheric Research and University of Colorado, 1989, 161 p.

Menon, S. and L. Rotstayn, 2006: The radiative influence of aerosol effects on liquidphase cumulus and stratiform clouds based on sensitivity studies with two climate models, Climate Dynamics, 27, 345-356, DOI 10.1007/s00382-006-0139-3.

Menon, S., and A.D. Del Genio, 2007: Evaluating the impacts of carbonaceous aerosols on clouds and climate. In Human-induced climate change: An interdisciplinary assessment, Cambridge University Press, (M. Schlesinger et al., Eds.).

Menon, S., A. D. Del Genio, Y. Kaufman, R. Bennartz, D. Koch, N. Loeb, and D. Orlikowski, 2008: Analyzing signatures of aerosol-cloud interactions from satellite retrievals and the GISS GCM to constrain the aerosol indirect effect, J. Geophys. Res., 113, D14S22, doi:10.1029/2007JD009442.

Noone, K. J. and A. D. Clarke, 1988: Soot scavenging measurements in Arctic snowfall, Atmos. Env., 22, 2773-2778.

Penner, J. E., C.C. Chuang, and K. Grant, 1998: Climate forcing by carbonaceous and sulfate aerosols. Clim. Dyn., 14, 839-851.

Proshutinsky, A.Y. and M.A. Johnson, 1997: Two circulation regimes of the wind-driven Arctic Ocean. J. Geophys. Res., 102(C6):12493-12514. Vol. 85, pp. 33-46. 
Quaas, J., O. Boucher, and U. Lohmann, 2005: Constrianing the total aerosol indirect effect in the LMDZ and ECHANM4 GCMs using MODIS satellite data, Atmos. Chem. Phys., 5, 9669-9690.

Rind, D., J. Perlwitz, P. Lonergan, and J. Lerner, AO/NAO response to climate change: 2, 2005: Relative importance of low- and high-latitude temperature changes, J. Geophys. Res., 110, doi:10.1029/2004JD005686.

Romanou, A., B. Liepert, G. A. Schmidt, W. B. Rossow, R. A. Ruedy, and Y. Zhang, 2007: 20th century changes in surface solar irradiance in simulations and observations, Geophys. Res. Lett., 34, doi:10.1029/2006GL028356.

Rotstayn, L. D. and J. E. Penner, Indirect aerosol forcing, quasi-forcing, and climate response, J. Clim., 14, 2960-2975, 2001.

Schmidt, G. A., et al., 2006: Present day atmospheric simulations using GISS ModelE: Comparison to in-situ, satellite and reanalysis data, J. Climate, 19, 153-192, doi:10.1175/JCLI3612.1.

Schulz, M., C. Textor, S. Kinne, Y. Balkanski, S. Bauer, T. Berntsen, T. Berglen, O. Boucher, F. Dentener, S. Guibert, I.S.A. Isaksen, T. Iversen, D. Koch, A. Kirkevg, X. Liu, V. Montanaro, G. Myhre, J.E. Penner, G. Pitari, S. Reddy, . Seland, P. Stier, and T. Takemura, 2006: Radiative forcing by aerosols as derived from the AeroCom present-day and pre-industrial simulations, Atmos. Chem. Phys., 6, 5225-5246.

Shindell, D.T., R.L. Miller, G.A. Schmidt and L. Pandolfo, 1999: Simulation of recent northern winter climate trends by greenhouse-gas forcing, Nature, 399, 452-455.

Shindell, D., 2007: Local and remote contributions to Arctic warming, Geophys. Res. Lett., 34, doi:10.1029/2007GL030221.

Sigmund, M., P. C. Siegmund, E. Manzini, and H. Kelder, 2004: A simulation of the 
separate climate effects of middle-atmosphere and troposphere CO2 doubling, J. Clim., 17, 2352-2367.

Takemura, T., T. Nozawa, S. Emori, T. Y. Nakajima, and T. Nakajima, 2005: Simulation of climate response to aerosol direct and indirect effects with aerosol transport-radiation model, J. Geophys. Res., 110, D02202, doi:10.1029/2004JD005029.

Warren, S. G., and W. J. Wiscombe, 1985: Dirty snow after nuclear war, Nature, 313, 467-470.

Warren, S.G., I.G. Rigor, N. Untersteiner, V.F. Radionov, N.N. Briazgin, Ye.I. Aleksandrov, and R. Colony, 1999: Snow depth on arctic sea ice, J. Climate, 12, 1814-1829.

Van Aardenne, J.A., Dentener, F.J., Olivier, J.G.J., Klein Goldewijk, C.G.M. and J. Lelieveld, 2001: A High Resolution Dataset of Historical Anthropogenic Trace Gas Emissions for the Period 1890-1990, Global Biogeochemical Cycles, 15(4), 909-928.

Wang, C., 2004: A modeling study on the climate impacts of black carbon, J. Geophys. Res., 109, doi:10.1029/2003JD004084.

Yao, M-S. and A. D. Del Genio, 1999: Effects of cloud parameterization on the simulation of climate changes in the GISS GCM, J. Clim., 12, 761-779. 


\section{List of Figures}

1 Aerosol optical depths for BC (x10) in a) 1890, b) 1995 and c) the change from 1890 to 1995; and for sulfate in d) 1890, e) 1995 and f) the change from 1890 to 1995. Simulations DIB with all aerosol effects are used, however other simulation pairs are similar. . . . . . . . . . . . . . . . . . . . . . 41

2 Instantaneous radiative forcing change from 1890 to 1995 for net aerosol direct effect a) at the TOA, b) at the surface and c) in the column; d) the BC-albedo instantaneous forcing change $(\mathrm{x} 10)$; units are $\mathrm{Wm}^{-2} \ldots \ldots . . . . . .442$

3 Indirect effect diagnostic changes from 1890 to 1995 for no GHG increase (top) and including GHG increase (bottom) for $\mathrm{ACF}_{I}$ or net cloud forcing (a, f), $\mathrm{Wm}^{-2}$; Warm stratus cloud optical depth (b, g); liquid water path $(\mathrm{c}, \mathrm{h}), \mathrm{kg}$ $\mathrm{m}^{-2}$; low level cloud cover (d, i), \%; cloud droplet number concentration (e, j), $\mathrm{cm}^{-3}$. Global $[$ Arctic] average change is provided. . . . . . . . . . . 43

4 Model BC deposition (ng BC/g precipitation) annual average (a) and NovemberApril (b); circles are observations referenced within Flanner et al., 2007. Model percent dry (relative to total) deposition, annual average (c) and November-April (d). Observation in (c) are from Davidson et al. (1985) and (d) Noone and Clarke (1988). Annual average scavenging ratio (BC in precipitation/air); observations are from Davidson et al. (1985). . . . . . . . 44 
5 Surface air temperature changes from 1890 to 1995 due to a) and f) aerosol direct effects, b) and g) also indirect effects, c) and h) also BC-albedo effect. d) and i) isolate the indirect effect (differences between b and a, and $g$ and $f$, respectively). e) and j) isalate the $\mathrm{BC}$-albedo effect (differences between c and b, and $\mathrm{h}$ and g, respectively). k) is observed change from 1890 to 2000 from the GISS Surface Temperature Analysis (http://data.giss.nasa.gov/gistemp/maps); white indicates lack of long-term observations. Top row is for experiments without GHG changes and second row experiments include changing GHG. Global [Arctic, 64-90N] average change is provided. . . . . . . . . . . . 45

6 Monthly Arctic changes (64-90N) in a) SAT, b) cloud cover, c) snow/ice cover and d) SLP for runs D (blue), Dg (blue dashed), DI-D (green), DIg-DI (green dashed), DIB-DI (red), DIBg-DIg(red dashed). . . . . . . . . . . . . 46

7 Cloud cover (\%) changes from 1890 to 1995 due to a) and f) aerosol direct effects, b) and g) also indirect effects, c) and h) also BC-albedo effect. d) and i) isolate the indirect effect. e) and j) isalate the BC-albedo effect. Top row is for experiments without GHG changes and bottom row experiments include changing GHG. Global [Arctic, 64-90N] average change is provided. . . . .

8 Snow and ice cover (\%) changes from 1890 to 1995 due to a) and f) aerosol direct effects, b) and g) also indirect effects, c) and h) also BC-albedo effect. d) and i) isolate the indirect effect. e) and j) isalate the BC-albedo effect. Top row is for experiments without GHG changes and bottom row experiments include changing GHG. Global [Arctic, 64-90N] average change is provided. . 48 
9 Change in $\mathrm{BC}$ removal (ng BC/g precipitation) from 1995 to 1890 for a) no change in GHG and b) change in GHG. . . . . . . . . . . . . . . . . . . . . 49

10 Sea level pressure (mb) changes from 1890 to 1995 due to a) and f) aerosol direct effects, b) and g) also indirect effects, c) and h) also BC-albedo effect. d) and i) isolate the indirect effect. e) and j) isalate the BC-albedo effect. Top row is for experiments without GHG changes and bottom row experiments include changing GHG. [Arctic, 64-90N] average change is provided. . . . . . 50

11 Stream function ( $\mathrm{x} 10^{9} \mathrm{~kg} \mathrm{~s}^{-1}$, positive=clockwise) changes from 1890 to 1995 due to a) and f) aerosol direct effects, b) and g) also indirect effects, c) and h) also BC-albedo effect. d) and i) isolate the indirect effect. e) and j) isalate the BC-albedo effect. Top row is for experiments without GHG changes and bottom row experiments include changing GHG. . . . . . . . . . . .

12 Shortwave radiative forcing change at the TOA $\left(\mathrm{W} \mathrm{m}^{-2}\right)$ changes from 1890 to 1995 due to a) and f) aerosol direct effects, b) and g) also indirect effects, c) and h) also BC-albedo effect. d) and i) isolate the indirect effect. e) and j) isalate the BC-albedo effect. Top row is for experiments without GHG changes and bottom row experiments include changing GHG. Global [Arctic, 64-90N] average change is provided. . . . . . . . . . . . . . 52

13 Monthly Arctic (64-90N) changes in a) net SW forcing at the tropopause, b) net LW forcing at the tropopause, c) LW upward surface forcing and d) LW clear sky forcing at the tropopause, for runs D (blue), Dg (blue dashed), DI-D (green), DIg-DI (green dashed), DIB-DI (red), DIBg-DIg(red dashed). . . 
14 Zonal mean temperature changes, ${ }^{\circ} \mathrm{C}$, for March (top) and July (bottom) for DE (a and f), DE+IE (b and g), DE+IE+BAE (c and h), IE (d, i) and BAE

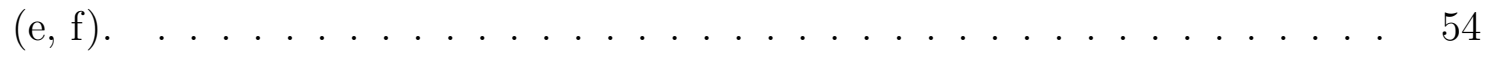


a) $B C 1890$
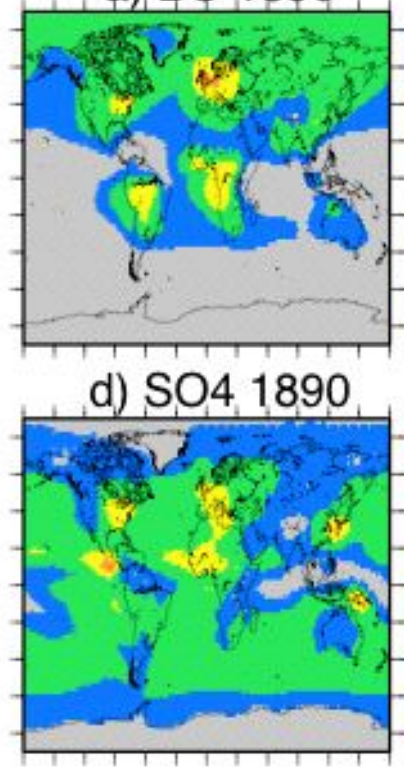

b) $\mathrm{BC} 1995$

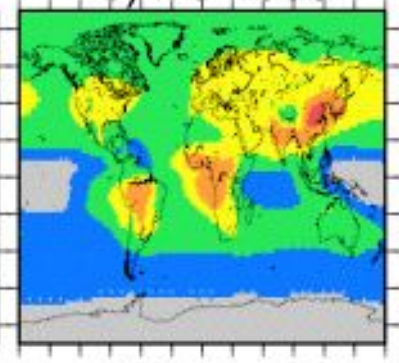

e) $\mathrm{SO} 41995$
C) $1995-1890$
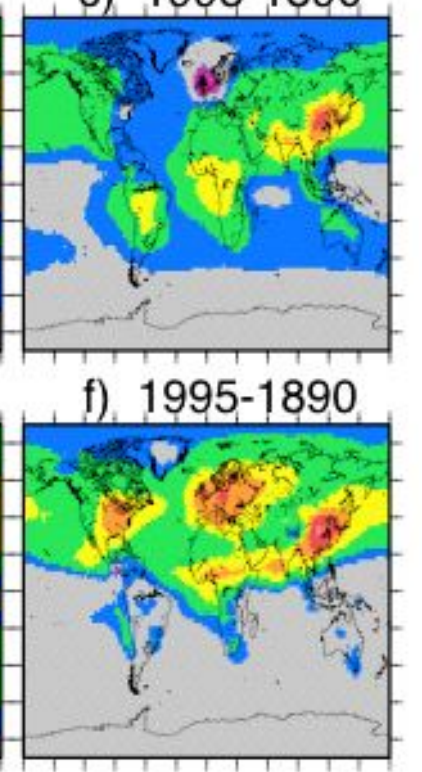

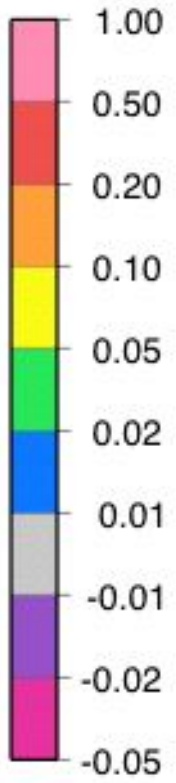

FIG. 1. Aerosol optical depths for BC (x10) in a) 1890, b) 1995 and c) the change from 1890 to 1995; and for sulfate in d) 1890, e) 1995 and f) the change from 1890 to 1995. Simulations DIB with all aerosol effects are used, however other simulation pairs are similar. 

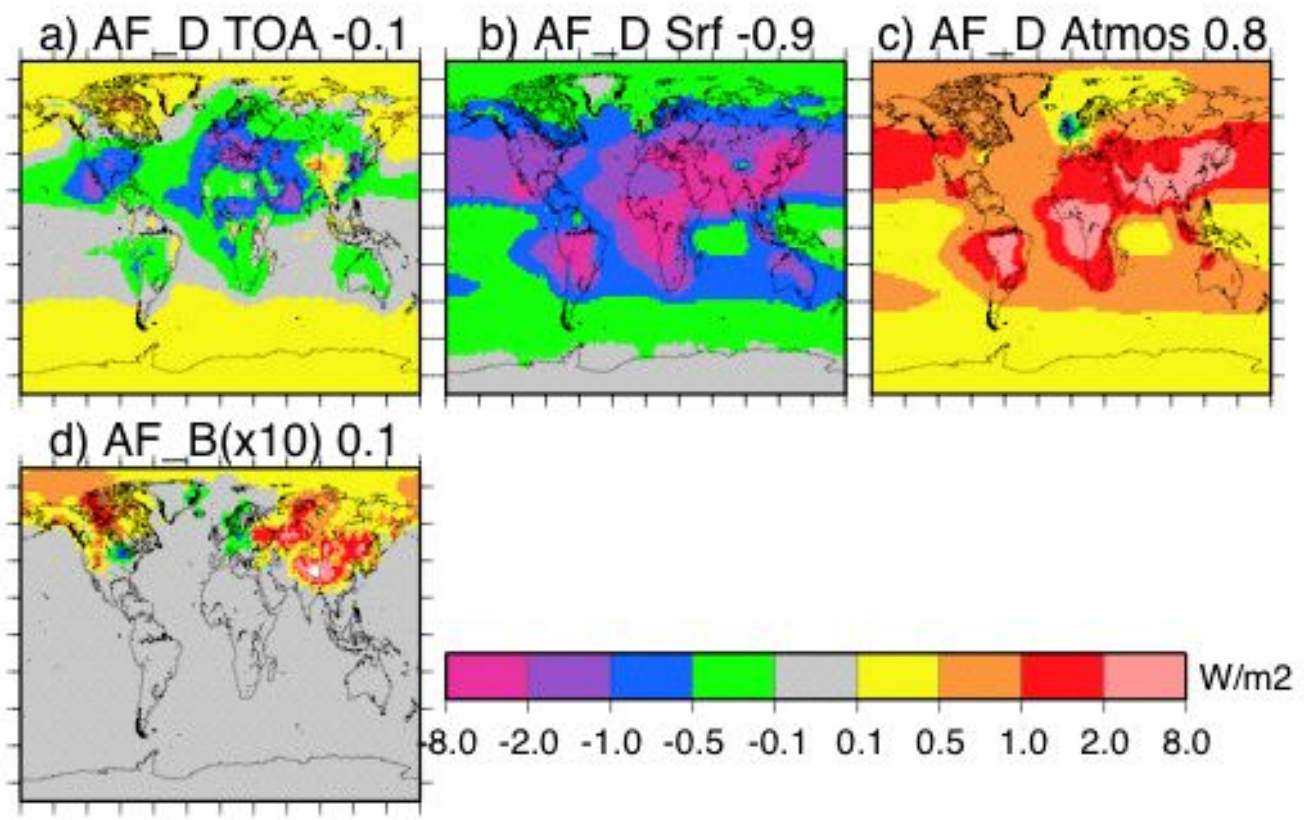

FiG. 2. Instantaneous radiative forcing change from 1890 to 1995 for net aerosol direct effect a) at the TOA, b) at the surface and c) in the column; d) the BC-albedo instantaneous forcing change (x10); units are $\mathrm{Wm}^{-2}$ 
a) ACF_I -1.2 [.15] b) COD 1.2[1.1] c) LWP 0.03 [-2.4]d) CC low .70 [.81] e) CDNC 30 [12]
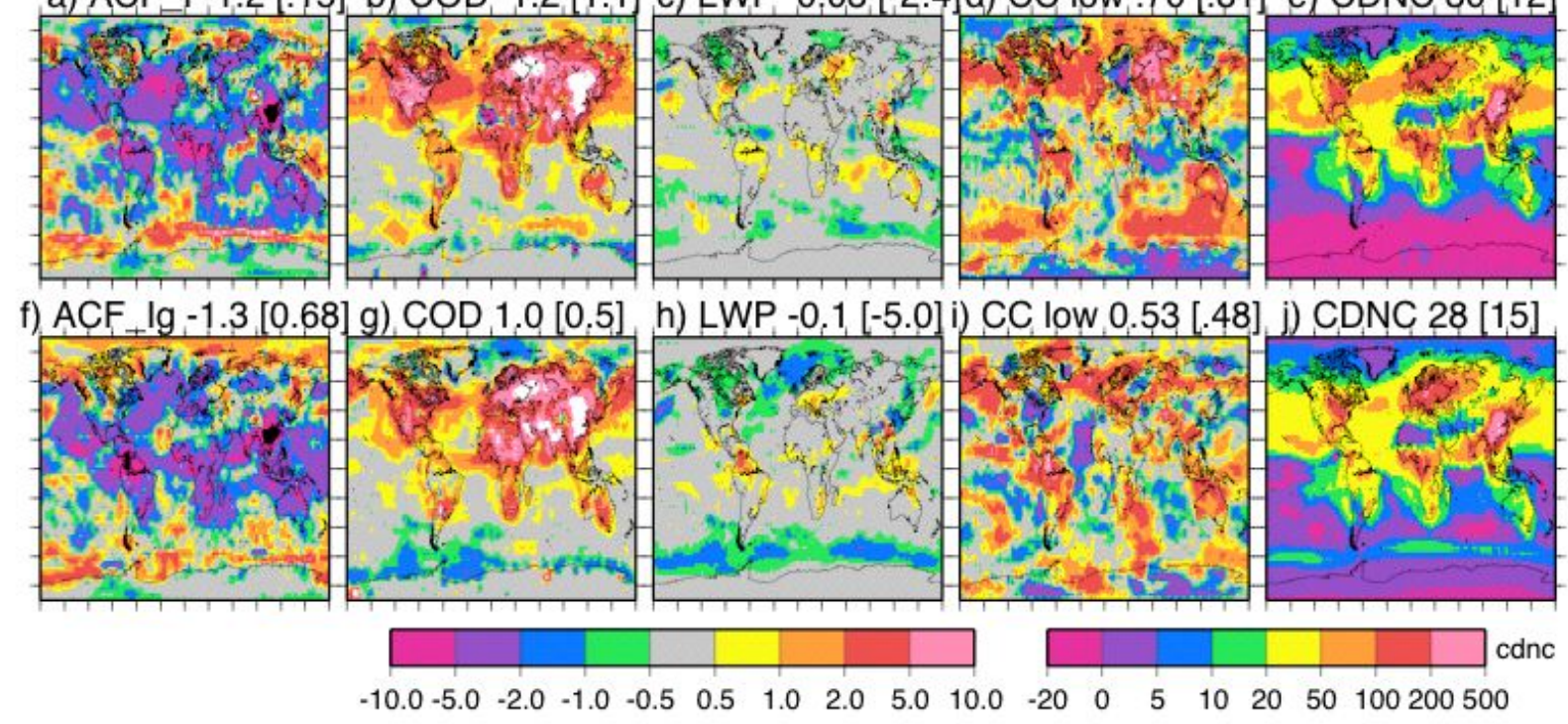

FIG. 3. Indirect effect diagnostic changes from 1890 to 1995 for no GHG increase (top) and including GHG increase (bottom) for $\mathrm{ACF}_{I}$ or net cloud forcing (a, f), $\mathrm{Wm}^{-2}$; Warm stratus cloud optical depth (b, g); liquid water path (c, h), $\mathrm{kg} \mathrm{m}^{-2}$; low level cloud cover (d, i), \%; cloud droplet number concentration $(e, \mathrm{j}), \mathrm{cm}^{-3}$. Global [Arctic] average change is provided. 

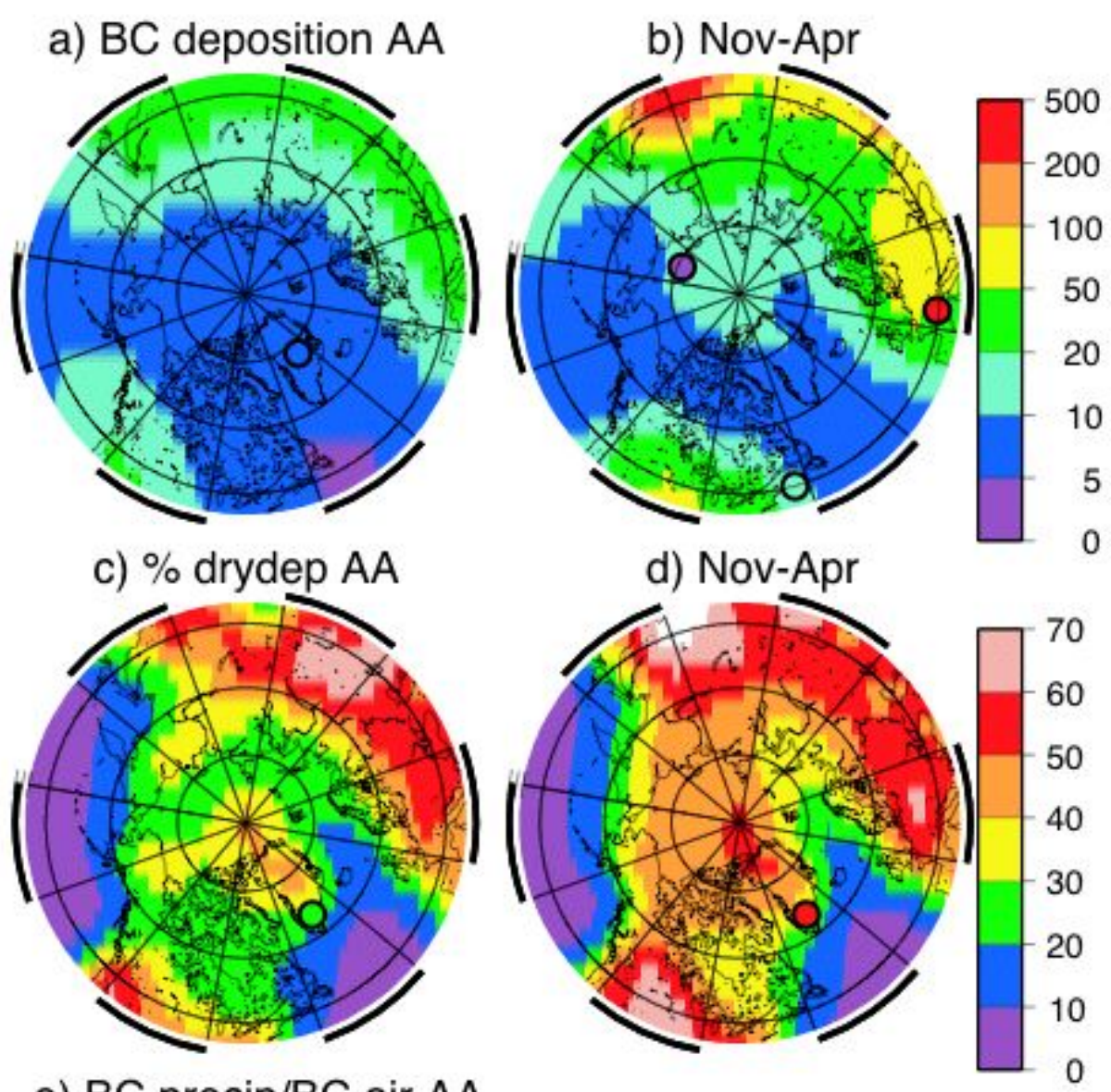

e) $B C$ precip/BC air AA

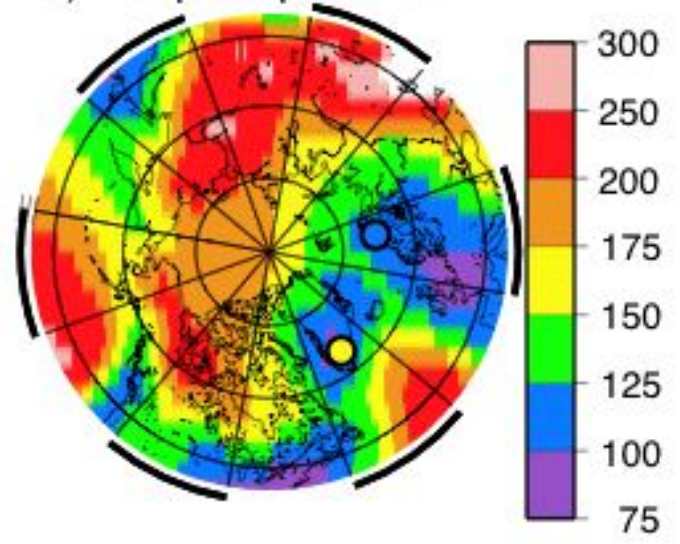

FIG. 4. Model BC deposition (ng BC/g precipitation) annual average (a) and NovemberApril (b); circles are observations referenced within Flanner et al., 2007. Model percent dry (relative to total) deposition, annual average (c) and November-April (d). Observation in (c) are from Davidson et al. (1985) and (d) Noone and Clarke (1988). Annual average 
a) $\mathrm{D}-0.15[-0.33]$

b) DI -1.2[-2.5]

c) DIB $-1.0[-2.0]$

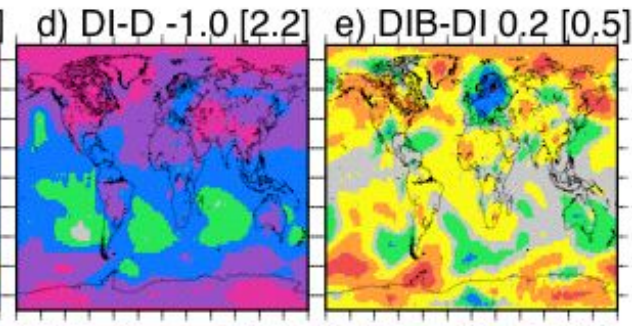

f) $\mathrm{Dg} 1.7[2.1]$
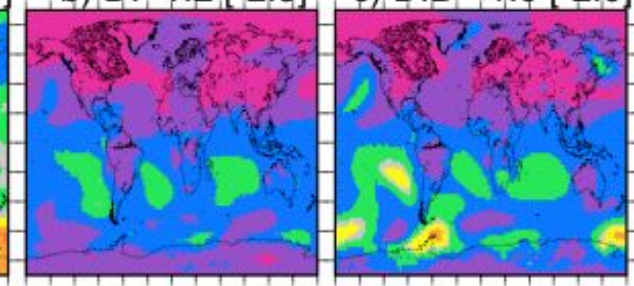

e) DIB-DI 0.2 [0.5]

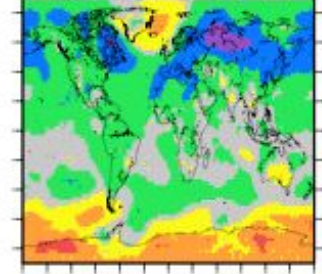

g) $\operatorname{Dlg} 0.9[0.6]$

h) DIBg 0.9 [0.8]

i) $\mathrm{Dlg}-\mathrm{Dg}-8$ [-1.5]j) DIBg-DIg 0. [.2]
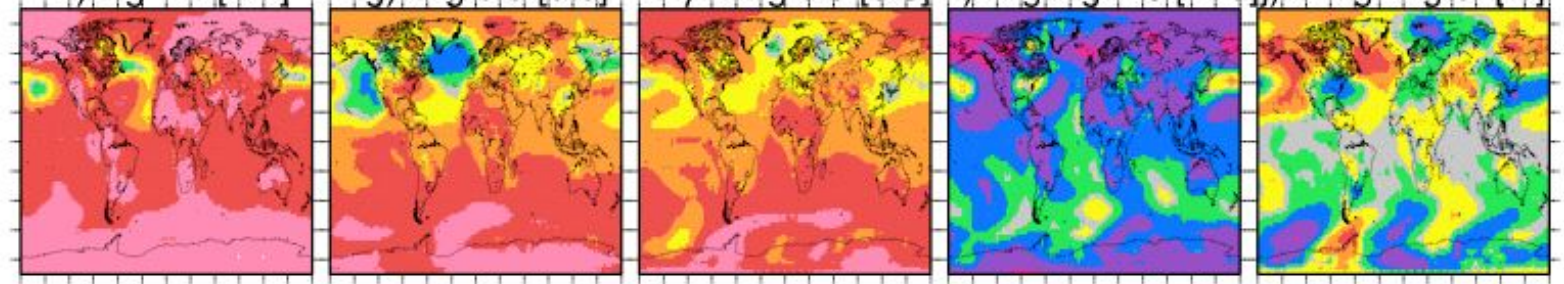

k) Obs 0.56
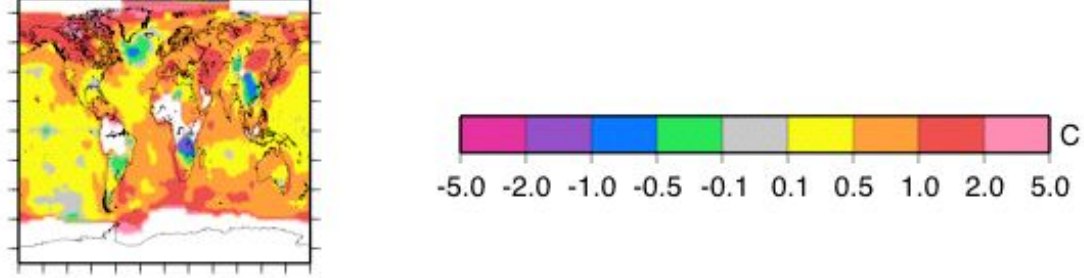

FIG. 5. Surface air temperature changes from 1890 to 1995 due to a) and f) aerosol direct effects, b) and g) also indirect effects, c) and h) also BC-albedo effect. d) and i) isolate the indirect effect (differences between $\mathrm{b}$ and $\mathrm{a}$, and $\mathrm{g}$ and $\mathrm{f}$, respectively). e) and j) isalate the BC-albedo effect (differences between $\mathrm{c}$ and b, and $\mathrm{h}$ and g, respectively). k) is observed change from 1890 to 2000 from the GISS Surface Temperature Analysis (http://data.giss.nasa.gov/gistemp/maps); white indicates lack of long-term observations. Top row is for experiments without GHG changes and second row experiments include changing GHG. Global [Arctic, 64-90N] average change is provided. 

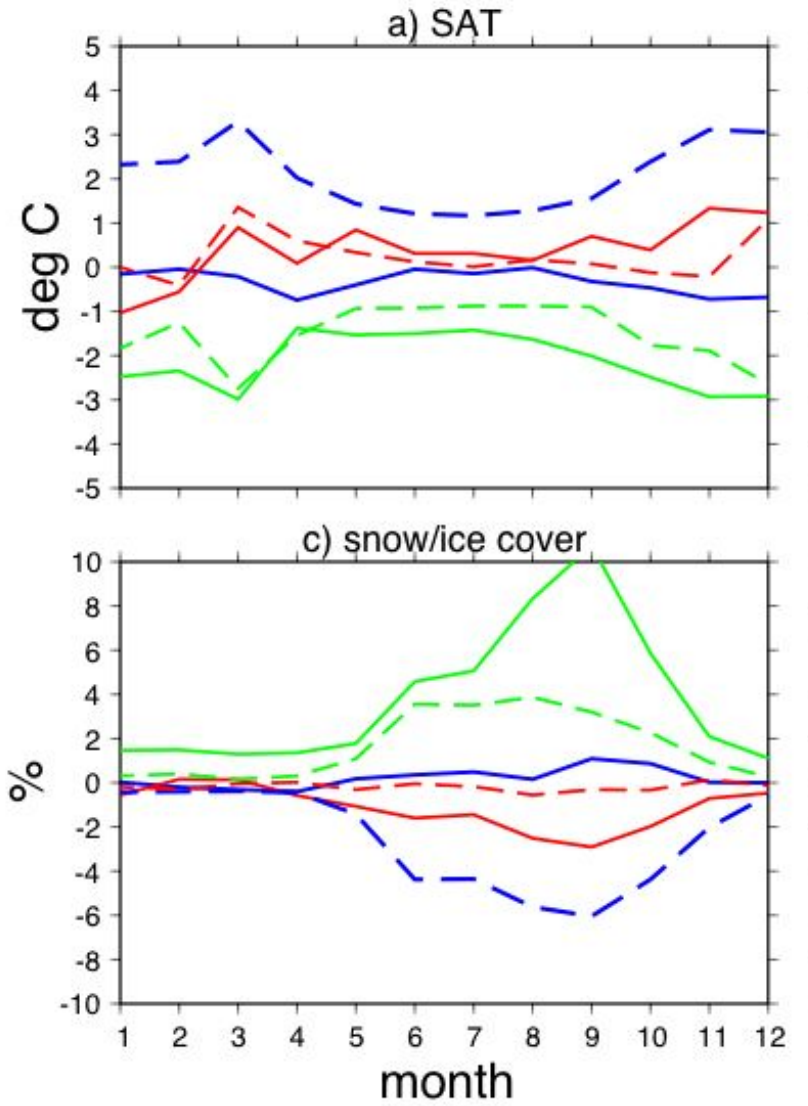

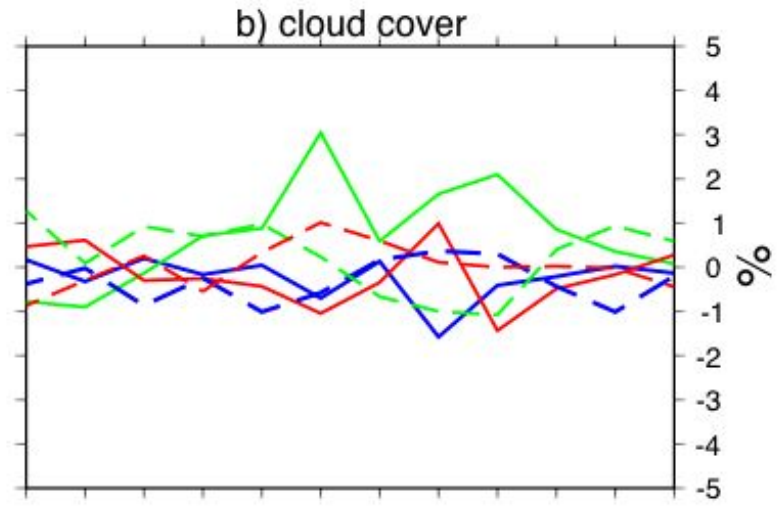

d) SLP

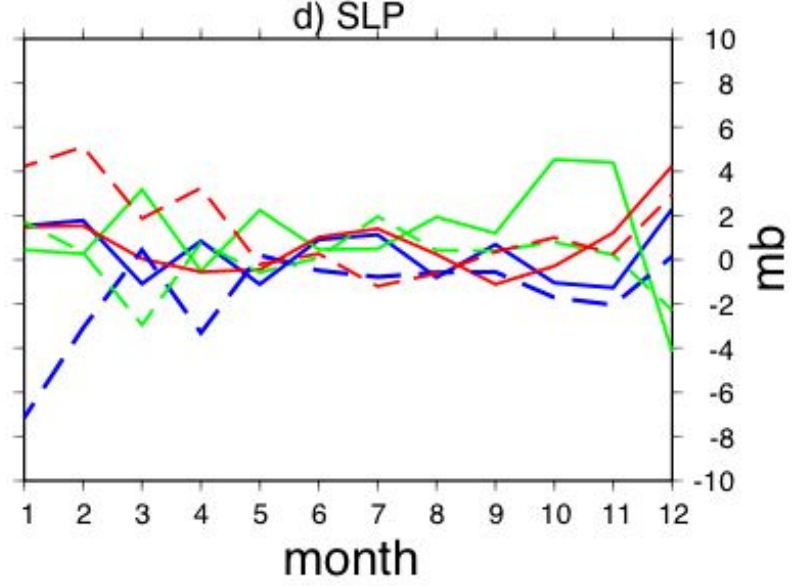

Fig. 6. Monthly Arctic changes (64-90N) in a) SAT, b) cloud cover, c) snow/ice cover and

d) SLP for runs D (blue), Dg (blue dashed), DI-D (green), DIg-DI (green dashed), DIB-DI (red), DIBg-DIg(red dashed). 
a) $D 0.05[-0,2]$

b) DI $0.6[0.5]$

c) DIB $0.5[0.3$

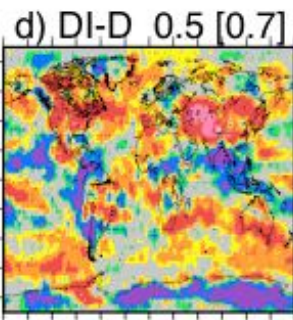

e) DIB-DI -0.1 [-0.2]
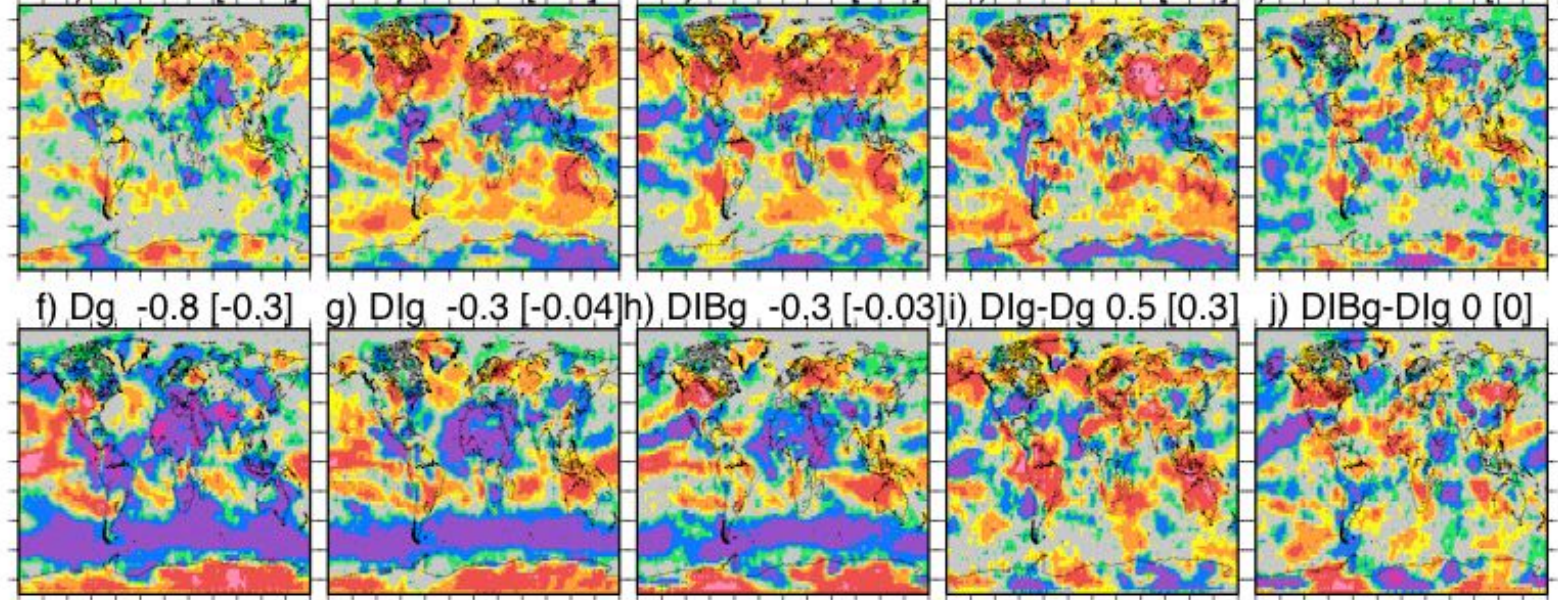

3]i) Dlg-Dg $0.5[0.3$
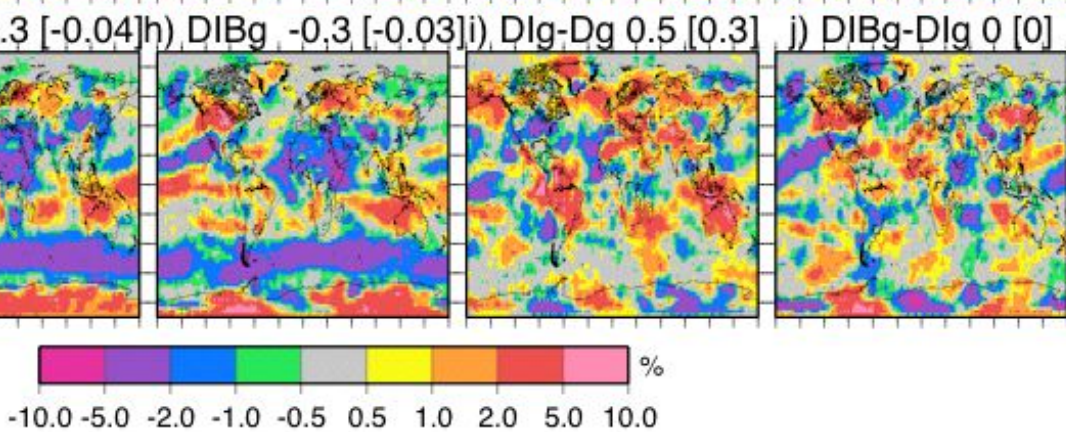

Fig. 7. Cloud cover (\%) changes from 1890 to 1995 due to a) and f) aerosol direct effects, b) and g) also indirect effects, c) and h) also BC-albedo effect. d) and i) isolate the indirect effect. e) and j) isalate the BC-albedo effect. Top row is for experiments without GHG changes and bottom row experiments include changing GHG. Global [Arctic, 64-90N] average change is provided. 


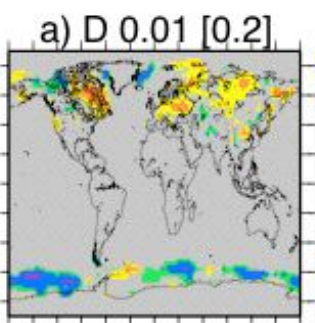

b) DI $1.0[4.0]$

c) DIB $0.7[2.8]$

d) DI-D 1.0 [3,8] e) DIB-DI -0.3 [-1,2]
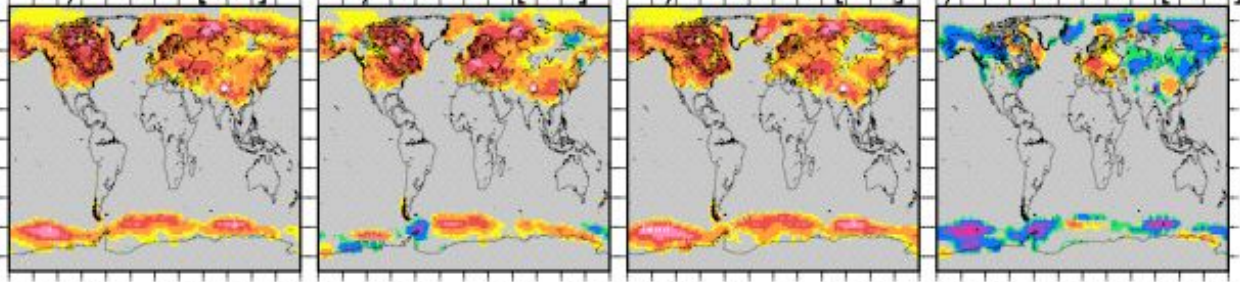

f) $\mathrm{Dg}-1.0[-2.5]$

g) $\mathrm{Dlg}-0.5[-0.9]$

h) $\mathrm{DIBg}-0.5[-1.1]$
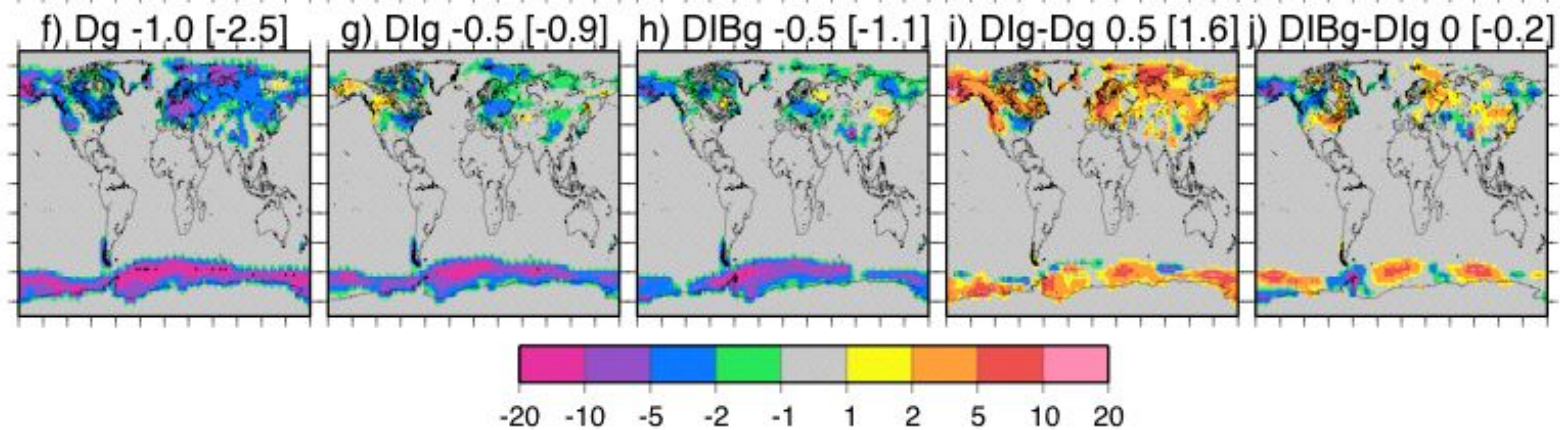

FIG. 8. Snow and ice cover (\%) changes from 1890 to 1995 due to a) and f) aerosol direct effects, b) and g) also indirect effects, c) and h) also BC-albedo effect. d) and i) isolate the indirect effect. e) and $\mathrm{j}$ ) isalate the BC-albedo effect. Top row is for experiments without GHG changes and bottom row experiments include changing GHG. Global [Arctic, 64-90N] average change is provided. 


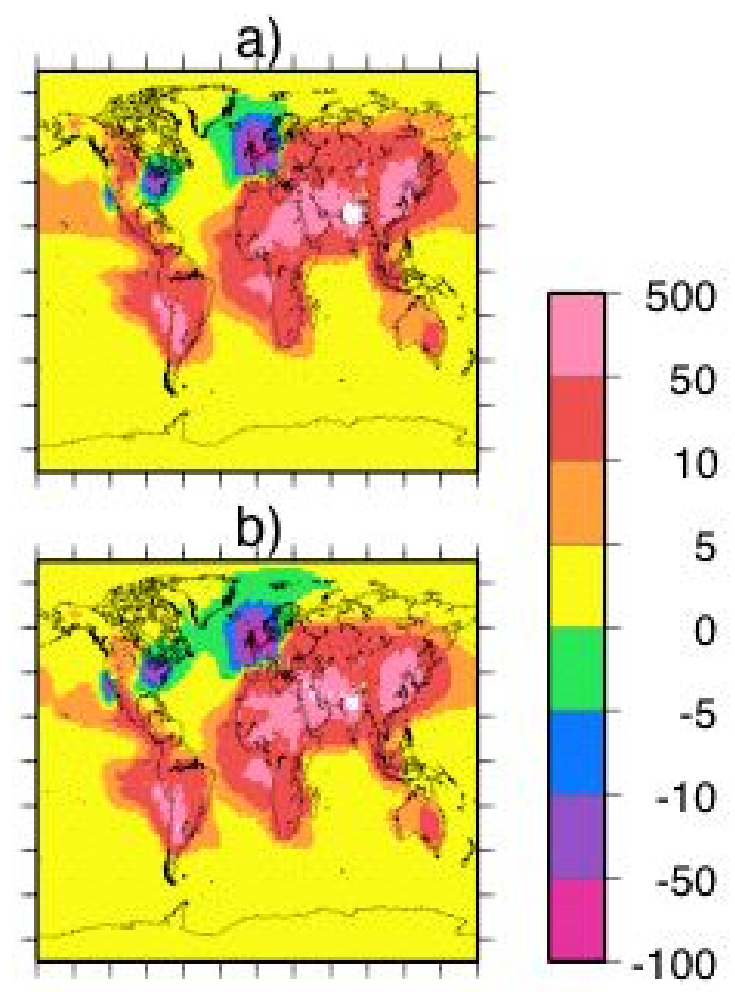

FIG. 9. Change in BC removal (ng BC/g precipitation) from 1995 to 1890 for a) no change in GHG and b) change in GHG. 
a) $\mathrm{D}[0,3]$

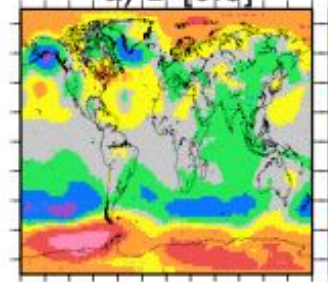

f) $\mathrm{Dg}[-1.6]$

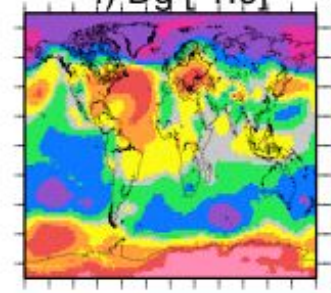

b) DI [1.5]

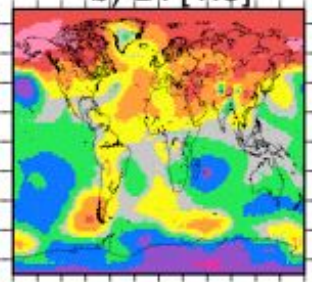

g) $\operatorname{Dlg}[-1.5]$

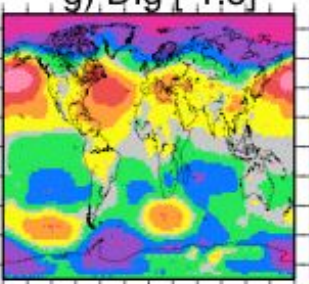

c) DIB [2.3]

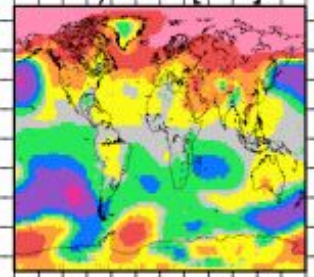

h) $\mathrm{DIBg}[-0.1]$ d) $\mathrm{DI}-\mathrm{D}[1,2]$

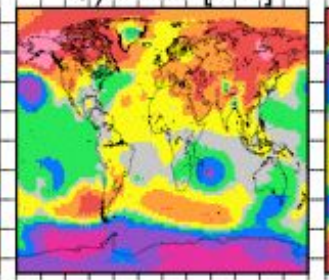

i) $\mathrm{Dlg}-\mathrm{Dg}$ [0.1]

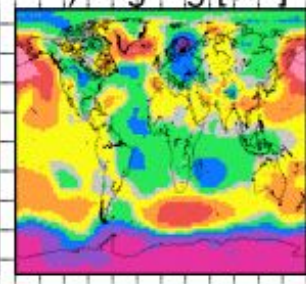

$\mathrm{mb}$

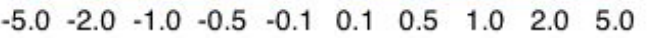

e) DIB-DI [0.8]

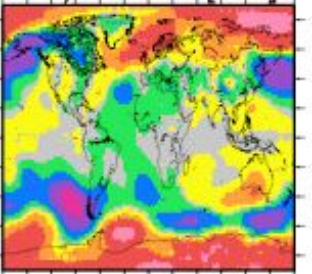

j) DIBg-DIg [1.4]

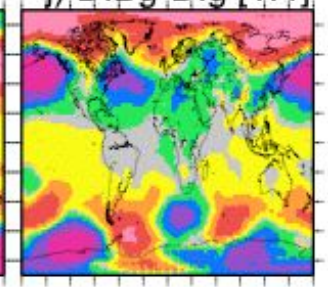

Fig. 10. Sea level pressure (mb) changes from 1890 to 1995 due to a) and f) aerosol direct effects, b) and g) also indirect effects, c) and h) also BC-albedo effect. d) and i) isolate the indirect effect. e) and $\mathrm{j}$ ) isalate the BC-albedo effect. Top row is for experiments without GHG changes and bottom row experiments include changing GHG. [Arctic, 64-90N] average change is provided. 


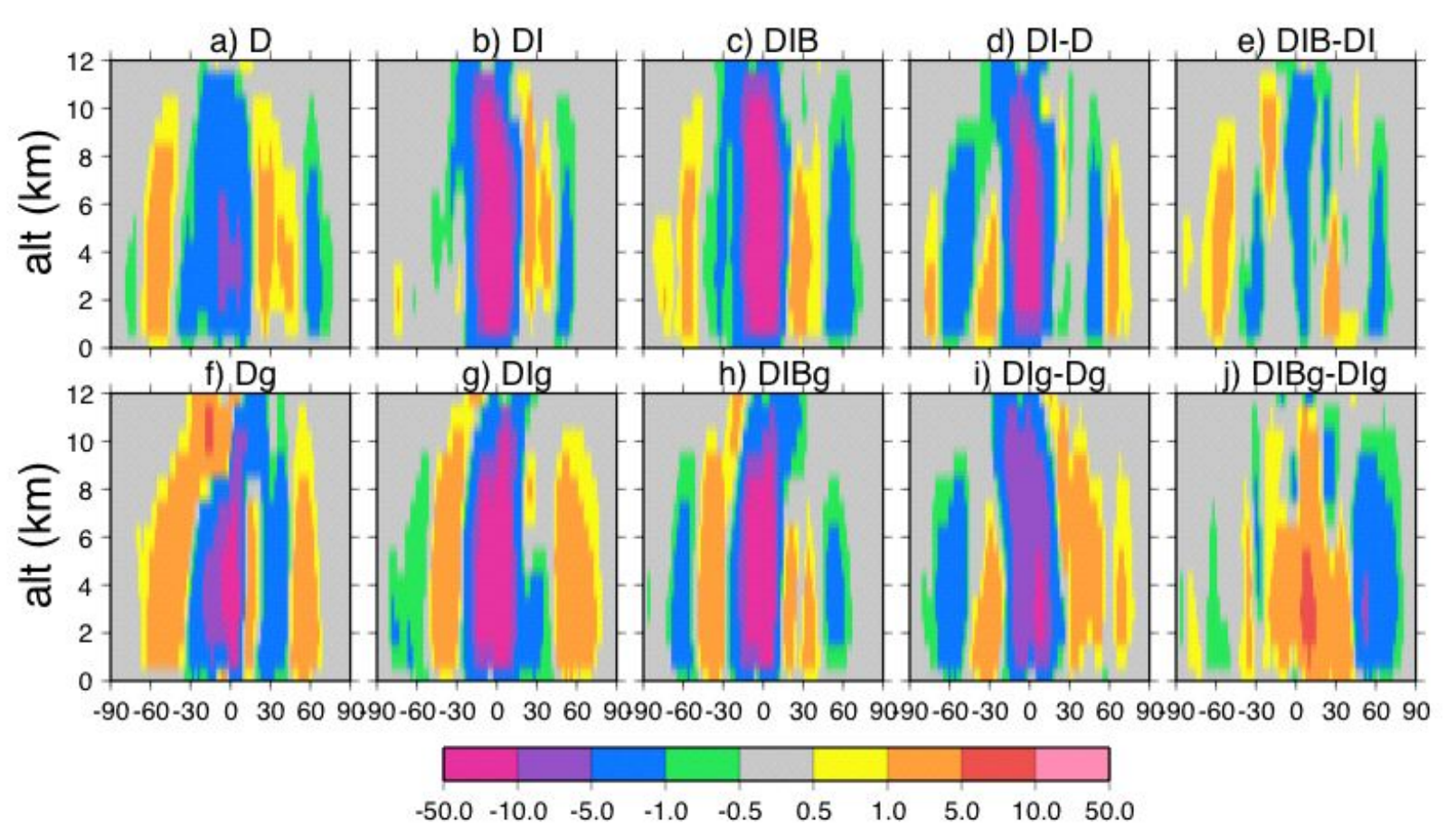

FIG. 11. Stream function $\left(\mathrm{x} 10^{9} \mathrm{~kg} \mathrm{~s}^{-1}\right.$, positive=clockwise $)$ changes from 1890 to 1995 due to a) and f) aerosol direct effects, b) and g) also indirect effects, c) and h) also BC-albedo effect. d) and i) isolate the indirect effect. e) and j) isalate the BC-albedo effect. Top row is for experiments without GHG changes and bottom row experiments include changing GHG. 
a) $D-0.2[0.7]$

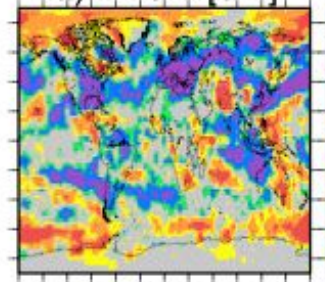

f) $\mathrm{Dg} 1.7[1.2]$

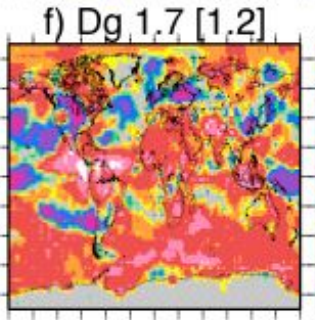

b) DI -2.3 [-2.2]

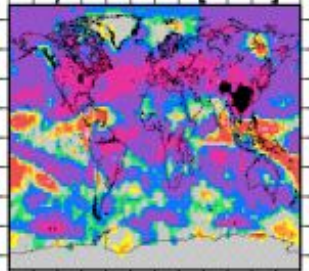

g) Dlg $-0.2[0.4]$

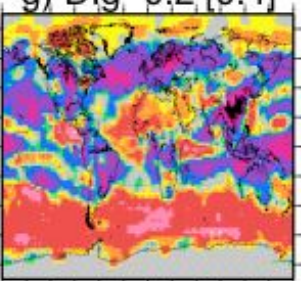

c) DIB - $2.0[-1.2]$
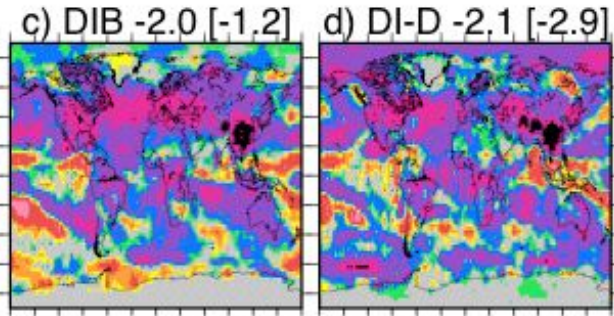

e) DIG-DI 0.3[1.0]

h) $\mathrm{DIBg}-0.3[0.4]$

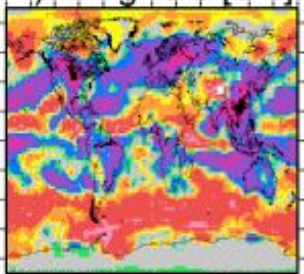

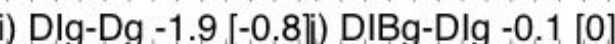
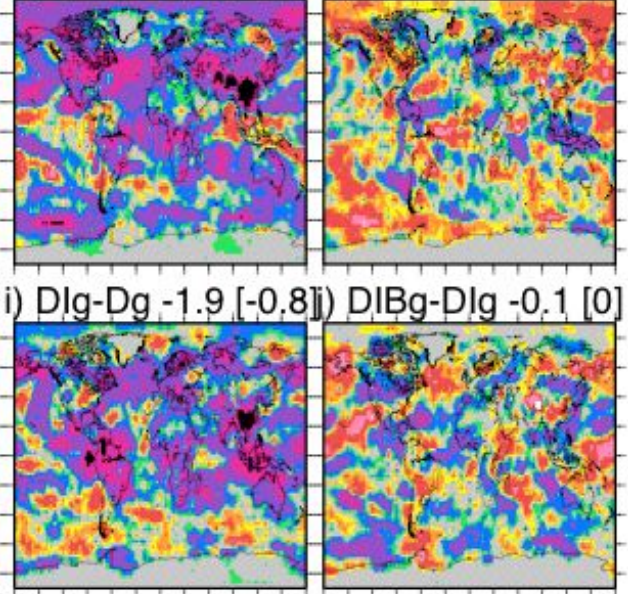

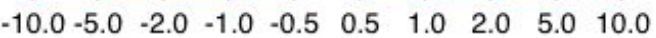

\section{$\mathrm{W} / \mathrm{m} 2$}




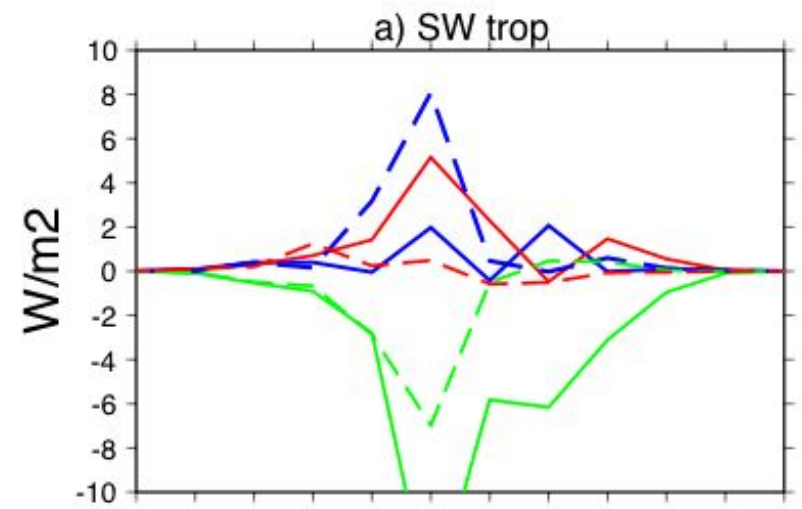

c) LW surf, up

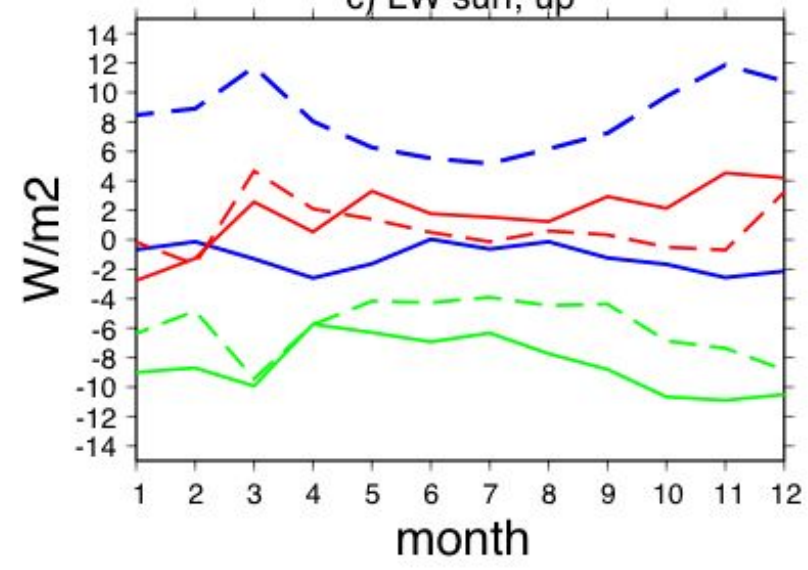

b) LW trop

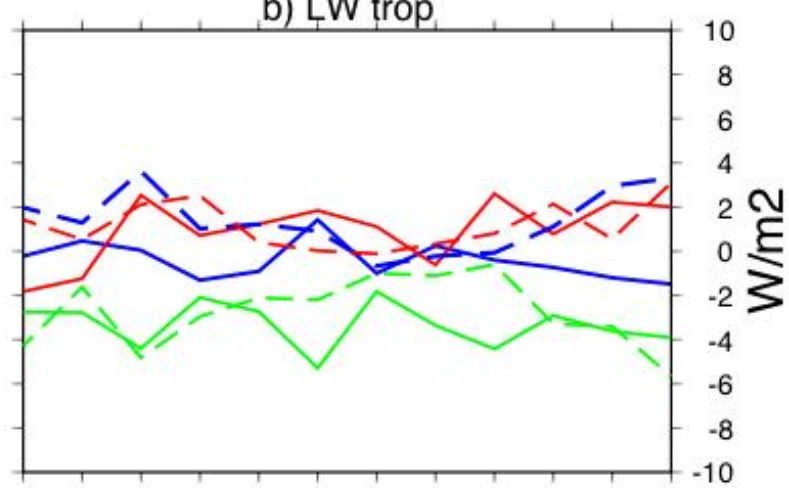

d) LW trop clr

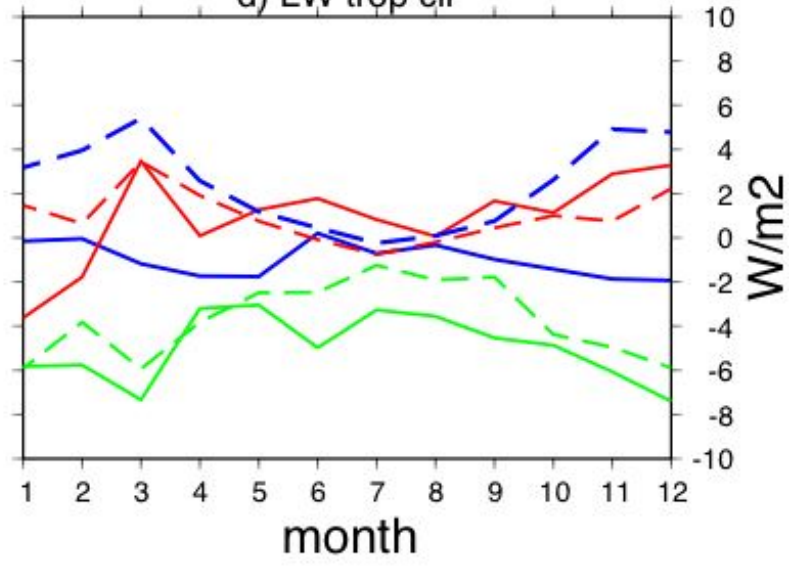

FIG. 13. Monthly Arctic (64-90N) changes in a) net SW forcing at the tropopause, b) net LW forcing at the tropopause, c) LW upward surface forcing and d) LW clear sky forcing at the tropopause, for runs D (blue), Dg (blue dashed), DI-D (green), DIg-DI (green dashed), DIB-DI (red), DIBg-DIg(red dashed). 


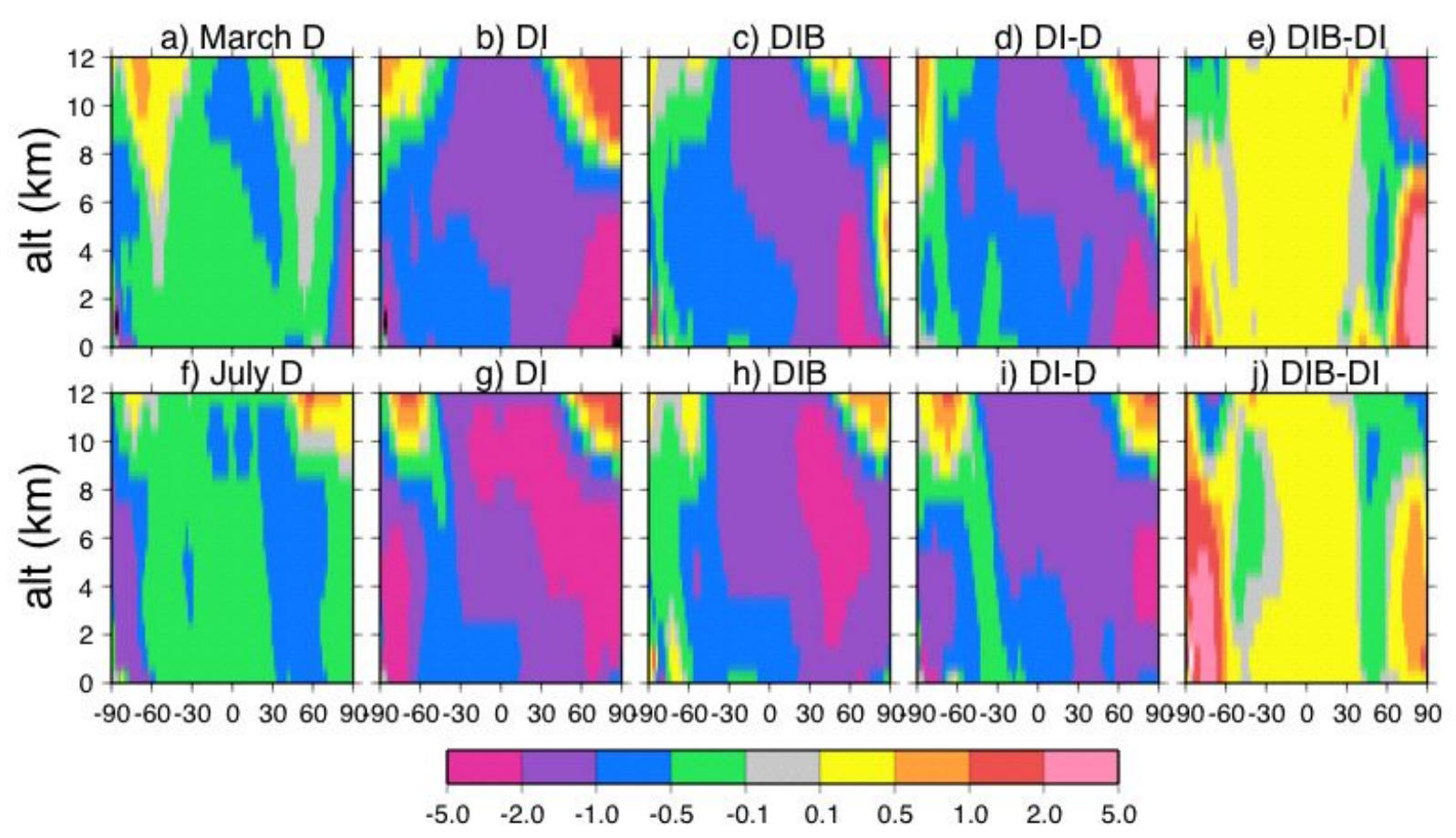

FIG. 14. Zonal mean temperature changes, ${ }^{\circ} \mathrm{C}$, for March (top) and July (bottom) for DE (a and f), DE+IE (b and g), DE+IE+BAE (c and h), IE (d, i) and BAE (e, f). 


\section{List of Tables}

1 Aerosol Characteristics . . . . . . . . . . . . . . . . . 56

2 Equilibrium Qflux Climate Experiment Definitions . . . . . . . . . . 57

3 Correlations Among Global [Arctic] Changes from 1890 to 1995 . . . . . . . 58

4 Indirect Effect Forcing Calculations . . . . . . . . . . . . . . . . 59

5 Comparison of BC-albedo effects with other studies . . . . . . . . . . 60 
TABle 1. Aerosol Characteristics

\begin{tabular}{|c|c|c|c|c|c|c|}
\hline Species & Emissions & Burden & AODx100 & $\mathrm{F}_{D}$ & $\operatorname{srf} \mathrm{F}_{D}$ & $\operatorname{clr} \mathrm{F}_{D}$ \\
\hline & & 1995 & & & & \\
\hline Sulfate & 106 & 0.40 & 5.3 & -0.7 & -0.7 & -0.8 \\
\hline $\mathrm{BC}$ & 8.2 & 0.19 & 0.38 & 0.5 & -0.7 & 0.3 \\
\hline $\mathrm{OM}$ & 59 & 1.2 & 1.9 & -0.3 & -0.7 & -0.7 \\
\hline \multirow[t]{2}{*}{ total } & & & 7.6 & -0.5 & -2.1 & -1.2 \\
\hline & & 1890 & & & & \\
\hline Sulfate & 32 & 0.2 & 2.6 & -0.4 & -0.4 & -0.5 \\
\hline $\mathrm{BC}$ & 4.0 & 0.08 & 0.16 & 0.2 & -0.3 & 0.1 \\
\hline $\mathrm{OM}$ & 41 & 0.8 & 1.3 & -0.2 & -0.5 & -0.5 \\
\hline \multirow[t]{2}{*}{ total } & & & 4.0 & -0.4 & -1.2 & -0.9 \\
\hline & & $1995-18$ & & & & \\
\hline Sulfate & 74 & 0.19 & 2.7 & -0.3 & -0.3 & -0.3 \\
\hline $\mathrm{BC}$ & 4.2 & 0.11 & 0.22 & 0.3 & -0.4 & 0.2 \\
\hline $\mathrm{OM}$ & 18 & 0.4 & 0.6 & -0.1 & -0.2 & -0.2 \\
\hline total & & & 3.5 & -0.1 & -0.9 & -0.3 \\
\hline
\end{tabular}

${ }^{1}$ Emissions are $\mathrm{Tg} \mathrm{S}$ or $\mathrm{C} \mathrm{yr}^{-1}$. Burdens are $\mathrm{Tg} \mathrm{S}, \mathrm{BC}$ or OM. $\mathrm{F}_{D}=$ instantaneous TOA $\mathrm{Wm}^{-2} ;$ srf=surface; $\mathrm{clr}=$ clear TOA. 
TABle 2. Equilibrium Qflux Climate Experiment Definitions

\begin{tabular}{|c|c|c|c|}
\hline Experiment & Aerosols & GHG & Effects \\
\hline \multirow[t]{2}{*}{$\mathrm{D}$} & 1890 & 1990 & Direct, control \\
\hline & 1995 & 1990 & Direct, perturbation \\
\hline \multirow[t]{2}{*}{ DI } & 1890 & 1990 & Direct \& Indirect, control \\
\hline & 1995 & 1990 & Direct \& Indirect, perturbation \\
\hline \multirow[t]{2}{*}{ DIB } & 1890 & 1990 & Direct, Indirect \& BC-albedo, control \\
\hline & 1995 & 1990 & Direct, Indirect \& BC-albedo, perturbation \\
\hline \multirow[t]{2}{*}{$\mathrm{Dg}$} & 1890 & 1890 & Direct, control \\
\hline & 1995 & 1990 & Direct, perturbation \\
\hline \multirow[t]{2}{*}{ DIg } & 1890 & 1890 & Direct \& Indirect, control \\
\hline & 1995 & 1990 & Direct \& Indirect, perturbation \\
\hline \multirow[t]{2}{*}{ DIBg } & 1890 & 1890 & Direct, Indirect \& BC-albedo, control \\
\hline & 1995 & 1990 & Direct, Indirect \& BC-albedo, perturbation \\
\hline
\end{tabular}


TABle 3. Correlations Among Global [Arctic] Changes from 1890 to 1995

\begin{tabular}{lrrrrrr}
\hline Fields & D & DI & DIB & Dg & DIg & DIBg \\
\hline CLD vs SAT & $-0.22[-0.24]$ & $-0.33[0.06]$ & $-0.35[-0.06]$ & $-0.27[-0.18]$ & $-0.31[0.05]$ & $-0.29[-0.42]$ \\
LOW CLD vs SAT & $-0.34[-0.33]$ & $-0.53[0.10]$ & $-0.54[-0.07]$ & $-0.41[-0.15]$ & $-0.48[0.01]$ & $-0.47[-0.45]$ \\
SAT vs SNO/ICE & $-0.40[-0.46]$ & $-0.48[-0.25]$ & $-0.51[-0.37]$ & $-0.32[-0.49]$ & $-0.31[-0.31]$ & $-0.33[-0.34]$ \\
CLD vs SNO/ICE & $0.16[0.33]$ & $0.32[0.44]$ & $0.35[0.34]$ & $0.13[0.22]$ & $0.15[0.28]$ & $0.21[0.27]$ \\
SLP vs SAT & $0.22[-0.27]$ & $-0.67[-0.40]$ & $-0.55[-0.09]$ & $-0.11[-0.21]$ & $-0.31[-0.44]$ & $-0.08[0.27]$ \\
\hline
\end{tabular}

${ }^{2}$ Dot product correlations among changes in fields, $\mathrm{CLD}=$ cloud cover, $\mathrm{SNO} / \mathrm{ICE}=$ snow and ice cover. 
TABLE 4. Indirect Effect Forcing Calculations

\begin{tabular}{|c|c|c|c|c|c|c|c|c|c|}
\hline & & $D$ & & & $D I$ & & & $I$ & \\
\hline Case & Net & SW & LW & Net & SW & LW & Net & SW & LW \\
\hline Qflux ACF & 0.55 & 0.48 & 0.07 & -0.62 & -0.41 & -0.21 & -1.17 & -0.89 & -0.28 \\
\hline Qflux $\mathrm{ACF}_{g}$ & 0.86 & 1.39 & -0.53 & -0.44 & -0.04 & -0.41 & -1.31 & -1.43 & 0.12 \\
\hline $\mathrm{SST}$ ACF & 0.62 & 0.63 & -0.01 & -0.62 & -0.55 & -0.07 & -1.24 & -1.18 & -0.06 \\
\hline SST TOA AF & -0.16 & -0.14 & -0.02 & -1.38 & -1.47 & 0.09 & -1.22 & -1.33 & 0.11 \\
\hline
\end{tabular}

${ }^{3} \mathrm{ACF}=$ anthropogenic cloud forcing; $\mathrm{ACF}_{g}$ includes GHG increases; SST has fixed SST; AF is TOA flux change 
TABLE 5. Comparison of BC-albedo effects with other studies

\begin{tabular}{lrrrrrrr}
\hline Study & source & $\Delta$ alb & $\Delta \mathrm{alb}_{A}$ & $\Delta \mathrm{F}$ & $\Delta \mathrm{SAT}$ & $\frac{\Delta F}{\Delta a l b}$ & $\frac{\Delta S A T}{\Delta a l b}$ \\
\hline This study & 20 th Cent & -0.12 & -1.1 & 0.01 & 0.18 & -0.08 & -1.5 \\
Flanner $(2007)^{5}$ & $\mathrm{BB}+\mathrm{FF}+\mathrm{BF}$ & $-0.40^{6}$ & -3.2 & $0.045^{7}$ & 0.12 & -0.11 & -0.3 \\
Hansen (2005) & $\delta$ alb & -0.08 & & 0.08 & 0.05 & -1 & -0.6 \\
Jacobson (2004) & $\mathrm{FF}+\mathrm{BF}$ & -0.4 & & 0.06 & 0.06 & -0.15 & -0.15 \\
HN (2004) & $\delta$ alb & -0.19 & -1.5 & 0.16 & 0.24 & -0.84 & -1.3 \\
\hline
\end{tabular}

${ }^{4}$ Studies: Flanner $=$ Flanner et al., $\mathrm{HE}=$ Hansen et al., $\mathrm{NH}=$ Hansen and Nazarenko. Sources: $\mathrm{BB}=$ biomass burning, $\mathrm{FF}=$ fossil fuel, $\mathrm{BF}=$ biofuel, 20th century is change during 20th century, $\delta$ alb is prescribed albedo change proportional to BC deposition in Koch (2001). $\Delta \mathrm{F}=$ global mean instantaneous change in forcing from $\mathrm{BC}$-albedo in $\mathrm{Wm}^{-2} \Delta$ alb $=$ global mean change in albedo, $\% . \Delta \mathrm{alb}_{A}=$ Arctic change in albedo, $\% . \Delta \mathrm{SAT}=$ change in SAT, C. ${ }^{5}$ average of high and low biomass burning simulations ${ }^{6}$ Global albedo change inferred from 0.12 (from NH and this study) x Arctic albedo ${ }^{7}$ TOA inferred from $0.9 \times$ surface forcing, Flanner et al., (2007) 